\title{
RESUMEN DE CONFERENCIAS
}

\section{Conferencia}

\section{Hipotiroidismo congénito: ¿qué se afecta además de la tiroides?}

\author{
Raúl Calzada León
}

$\mathrm{E}$

l estudio de recién nacidos con hipotiroidismo congénito detectado por el tamiz neonatal, ha permitido determinar que las siguientes variables inciden en la morbilidad de los pacientes:

1. Inicio intrauterino: Edad ósea en rodilla retrasada con respecto a la edad gestacional al momento del nacimiento, en ausencia de prematurez, retraso de crecimiento intrauterino, cromosomopatías, ni alteraciones durante la gestación

2. Inicio extrauterino: Edad ósea en rodilla acorde con la edad gestacional al momento del nacimiento, en ausencia de prematurez, retraso de crecimiento intrauterino, cromosomopatías, ni alteraciones durante la gestación.

3. Atireosis: Ausencia ultrasonográfica y gammagráfica de tiroides, con tiroglobulina más de 3 desviaciones estándar por debajo de la media, anticuerpos antitiroglobulina negativos y ecuación discriminante con signo positivo.

4. Nódulo tiroideo: Detección gammagráfica de un nódulo tiroideo, con tiroglobulina entre 0 y 3 desviaciones estándar por debajo de la media, anticuerpos antitiroglobulina negativos y ecuación discriminante con signo negativo.

La ecuación discriminante es: $(\mathrm{T} 3)(-0,015)+(\mathrm{Tg})(-0,035)+2,4$.

Al analizar estos cuatro parámetros, encontramos una asociación significativa con las siguientes alteraciones:

a. Atireosis e hipotiroidismo de inicio intrauterino con malformaciones, cardiopatías, alteraciones del llanto y daño neurológico.

b. Atireosis o nódulo ectópico con hipotiroidismo de inicio intrauterino con trastornos de la deglución.

c. Atireosis, independientemente de si el inicio es intra o extrauterino con alteraciones del oído medio.

En particular, la descripción de cada grupo de alteraciones es:

\section{Malformaciones}

- En $24 \%$ de los pacientes.

- Cardiopatías congénitas, las más frecuentes.

- Alteraciones renales, óticas, labio y paladar hendidos, esqueléticas.
- Síndromes genéticos: Hirschprung, Beckwith-Wiedemann, secuencia Pierre Robin, osteodistrofia de Albright, asociación VATER, displasia frontonasal.

- No se encontraron malformaciones urológicas ni neurológicas.

\section{Cardiopatías}

- Riesgo relativo 4-7x

- Defectos del septum (CIA > CIV)

- Persistencia de conducto arterioso

- Estenosis de válvula y arteria pulmonar

- Estenosis de válvula tricúspide

Trastornos de la deglución

- Incoordinación entre las fases oral y faríngea

- Incoordinación de la fase faríngea con la fase esofágica

- Incoordinación de la fase faríngea con la respiración y la deglución

- Incoordinación de la fase esofágica con la respiración y la deglución

Trastornos de oído medio

- Alteraciones en la osificación del laberinto

- Alteraciones por frecuencia y amplitud en 1 y $1.5 \mathrm{kHz}$

Llanto

- Sin vibración en cuerdas bucales (similar a gruñido, no a llanto).

Alteraciones neurológicas

- Inmadurez de la cisura calloso-marginal (cíngulo), relacionada con la formación del cuerpo calloso y con la migración neuronal.

- Menor Coeficiente General de Desarrollo.

- Retraso en la mielinización de corteza visual, auditiva, hipocampo y cerebelo.

- EEG: Ritmos lentos y bajo voltaje.

- Mayor cantidad de episodios de apnea y de hipopnea.

Con lo anterior se pueden definir las morbilidades que se deben buscar en los pacientes para proporcionar un mejor programa de estimulación psicomotriz. 


\title{
Conferencia
}

\section{La etapa fetal extrauterina}

\author{
Raúl Calzada León
}

$\mathrm{E}$ l Homo sapiens tiene una gestación normal pero que debe terminar de manera prematura debido principal-

mente a los siguientes tres eventos:

- Ganancia de masa cerebral

- Deambulación bípeda

- Dilema obstétrico-metabólico

\section{Ganancia de masa cerebral}

El incremento en la cantidad y frecuencia de consumo de alimentos de origen animal ocasionó no solo un descenso en el consumo de fibra no digerible de origen vegetal, sino que además permitió ingerir alimentos con proteínas de mayor valor biológico, mayor contenido de grasas, y mayor cantidad de calorías por volumen ingerido, lo que disminuyó la energía utilizada por el intestino para procesos digestivos, con lo que se pudo aumentar el aporte energético al cerebro, de tal manera que en forma inversamente proporcional a la disminución de la longitud y volumen intestinal, aumentó significativamente y en un lapso relativamente corto de tiempo el volumen cerebral.

Así, en poco más de 3 millones de años, aumentó el volumen del cerebro desde 450 cc en A. aferensis hasta 1.450 cc en el H. sapiens.

La ganancia de masa cerebral produjo un aumento del perímetro y del diámetro del cráneo, no solo en la vida adulta sino desde la etapa fetal.

\section{Deambulación bípeda}

Al cambiar el hábitat tropical por el clima relativamente más seco y caliente de las sabanas, obligó a desplazarse en posición permanentemente erguida y apoyado en dos piernas que se alternan durante la deambulación.

Es probable que esta postura se haya iniciado para facilitar otear el horizonte por encima de la vegetación herbácea en busca de árboles o depredadores, pero un beneficio importante es que se asoció a un considerable ahorro energético para el desplazamiento, lo que permitió avanzar distancias mayores en menor tiempo.

El ancho máximo de la pelvis está determinado por las limitaciones de equilibrio, velocidad y consumo de energía de la deambulación bípeda, y ésta se hace más eficiente si la pelvis es más estrecha y con una angulación más vertical.

\section{Dilema obstétrico-metabólico}

La deambulación bípeda originó una disminución del diámetro del canal obstétrico $(38,5 \mathrm{~cm})$, que solo permite el paso de un perímetro cefálico máximo de $37,0 \mathrm{~cm}$, lo que obligó a que el parto se realizara a una edad gestacional inusualmente corta ( 9 meses).

De hecho, la gestación de los humanos debería durar por lo menos 18 meses para que los recién nacidos tuvieran el mismo grado de maduración que las crías de los gorilas y chimpancés, que corresponde al $40 \%$ de la de individuos adultos, en vez del $25 \%$ que se observa en los humanos, pero ello implicaría un perímetro cefálico $3 \mathrm{~cm}$ más grande, lo que impediría su paso por el canal del parto.

Por otro lado, la tasa metabólica del feto es muy alta y la vida intrauterina requiere aproximadamente $81.000 \mathrm{Kcal}$ en un periodo de 9 meses, en tanto que otros primates requieren 2.,000 a 25.000 Kcal en un período de 7-8 meses. A esto hay que agregar que el aumento máximo de la tasa metabólica de una mujer durante la gestación es 2,5 veces mayor que su metabolismo basal, y que esto se alcanza al noveno mes de gestación, por lo que el balance entrópico solo puede mantenerse durante un máximo de nueve meses.

Por todo lo anterior, todos los nacimientos humanos tras un periodo de gestación de 40 semanas deben considerarse prematuros y sus productos como inmaduros, y éstos deben mantener las condiciones fetales de regulación de la temperatura corporal, del crecimiento físico y del desarrollo neurológico durante otras 40-44 semanas, periodo en el cual el cerebro alcanza el $50 \%$ de su tamaño final, la locomoción se hace bípeda, pueden reconocer y responder a estímulos ambientales que faciliten su sobrevida, y logran comunicarse con efectividad a distancia para que los adultos puedan reconocer sus necesidades.

Por ejemplo, al momento del nacimiento, el producto tiene que generar suficiente energía térmica para mantener su temperatura corporal en límites homeotérmicos $\left(36,5\right.$ a $\left.37,5^{\circ} \mathrm{C}\right)$, pero la producción de hormonas tiroideas y la preservación de temperatura solo permiten que la temperatura crítica inferior (temperatura ambiental a partir de la cual se tienen que aumentar los procesos oxidativos para generar calor que se transforma en temperatura corporal), sea de $33^{\circ} \mathrm{C}$ y tarda 18 a 24 meses para disminuirla a $28{ }^{\circ} \mathrm{C}$ (temperatura crítica inferior de adultos). Además se tarda 24 meses en acumular suficiente reserva energética para permitir periodos prolongados de ayuno, similares a los de los adultos.

Sin embargo, un parto biológicamente prematuro también tiene sus ventajas, pues el neonato está expuesto a una estimulación sensorial más diversa que la que existe en el ambiente intrauterino, lo que produce una mayor plasticidad neurológica y determina una mayor velocidad de aprendizaje.

El hecho incontrovertible es que los cuidados posnatales para garantizar la sobrevida deben prolongarse durante un periodo más prolongado que el de otros primates, y así por ejemplo: 
- Los mamíferos destetan a sus crías cuando triplican y los primates cuando cuadruplican el peso al momento del nacimiento.

- Para el chimpancé y el gorila, la duración de la lactancia es seis veces superior a la duración de la gestación.

Bajo estos conceptos, la edad natural de destete para los humanos sería como mínimo de seis veces la duración del periodo gestante, es decir, a los 4,5 años de edad.

Por otro lado, existe una relación entre el tamaño y el gra- diente de maduración del cerebro y la aparición del primer molar, por lo que el tiempo mínimo de alimentación con leche materna en los primates es de 3,5 años, lo que traducido a Homo sapiens representaría una edad de 6 años en las mujeres y 7 años en los varones.

Finalmente, la alimentación con leche materna termina en los primates cuando sus crías logran su autonomía inmunológica, lo que en términos humanos tarda seis años.

\title{
Conferencia
}

\section{Mecanismos del síndrome de resistencia a hormonas tiroideas $(\mathrm{RTH})$}

\author{
Guillermo Juvenal
}

$\mathrm{E}$ RTH puede estar asociado a fallas en los transportadores para hormonas tiroideas o a fallas del receptor para hormonas tiroideas (TR).

En lo que se refiere a los transportadores, se han caracterizado varios de ellos localizados en la membrana plasmática. El síndrome de Allan-Herndon-Dudley es causado por mutaciones en el transportador MCT8. Este transportador es específico para $\mathrm{T}_{4}$ y $\mathrm{T}_{3}$, aunque no se puede descartar a alguna otra molécula, y juega un rol fundamental en la captación de $\mathrm{T}_{3}$ por parte de células neuronales. Hasta el momento, se han descrito aproximadamente un centenar de pacientes. Las mutaciones encontradas hasta ahora incluyen sustituciones, deleciones, mutaciones sin sentido y falso sentido.

Los pacientes con el síndrome de Allan-Herndon-Dudley presentan una elevación de la $\mathrm{T}_{3}$ sérica y disminución de $\mathrm{T}_{4} \mathrm{y}$ $\mathrm{rT}_{3}$. La TSH puede estar normal o levemente aumentada. En lo que respecta al fenotipo, es un síndrome neurológico ligado al cromosoma X, causando un retraso del desarrollo, severo retraso mental, falta de adquisición del lenguaje y alteraciones neuromotoras. Al estar ligado al X, todos los pacientes estudiados son hombres. Las mujeres heterocigotas son portadoras y no presentan defectos neurológicos.

Al no haber, en la actualidad, un tratamiento posible para esta patología, se están ensayando análogos de hormonas tiroideas (ácido 3,5-diiodotiropropiónico) que puedan atravesar la barrera hematoencefálica, sin dependencia de la presencia de transportadores y que conserven su actividad genómica.

En lo que se refiere a las fallas al síndrome de resistencia por fallas del TR, es una enfermedad hereditaria, de transmisión autosómica dominante, caracterizada por una sensibilidad reducida de los tejidos a las hormonas tiroideas, asociada a niveles aumentados de $\mathrm{T}_{4} \mathrm{y} \mathrm{T}_{3}$ séricas y niveles de TSH levemente altos o inapropiadamente normales. Se han descrito más de 3.000 pacientes con más de 170 mutaciones diferentes, que presentan un fenotipo variable, aunque con algunas características comunes tales como bocio, taquicardia, osteoporo- sis, disturbios emocionales, problemas de aprendizaje, etc. La severidad de la RTH depende del tipo de mutación observada, además de los antecedentes genéticos y factores ambientales, tal como se puede observar en los diversos fenotipos de los animales con diferentes mutaciones en un mismo tipo de receptor. El receptor para hormonas tiroideas es un factor de transcripción que según el caso puede funcionar como un activador o represor de la transcripción. Los receptores para las hormonas tiroideas están codificados por dos genes diferentes, TR $\alpha$ y TR $\beta$.

Este síndrome es causado por una mutación en el TR $\beta$ en la mayoría de los pacientes, que son en gran parte heterocigotas, o sea, poseen solamente un alelo mutado del TR $\beta$. Se conocen pocos pacientes homocigotos, los cuales poseen fenotipos más severos. En una familia se ha encontrado una deleción del TR $\beta$, siendo los heterocigotas normales. Esto se debe a que el receptor mutado funciona como un antagonista de la copia normal. Por el contrario, la deleción de uno de los alelos no afecta al mecanismo de acción del receptor codificado por el otro alelo. En el caso de los pacientes homocigotos para la deleción (las dos copias ausentes), éstos presentaban ceguera a los colores, sordomudez (el TR $\beta$ participa en la maduración de la cóclea y el desarrollo de los fotorreceptores, conos, que median la visión de los colores) y signos de hipotiroidismo, aunque no tan severos como los observados en el paciente que presentaba la mutación en los dos alelos de TRß.

La mayoría de las mutaciones encontradas, en el dominio de unión a la hormona, determinan que el TR $\beta$ tenga poca afinidad por la $\mathrm{T}_{3}$. Otras mutaciones en el dominio bisagra interfieren en el correcto plegamiento del receptor, en tanto que otras interfieren en el intercambio de correpresores por coactivadores (proteínas necesarias para una eficiente transcripción del gen). No se han encontrado mutaciones en la región de unión al ADN o de dimerización. Esto podría deberse a que sujetos heterocigotos con estas mutaciones no presentarían síntomas de RTH. Dado que el TR $\alpha 1$ es la isoforma que pre- 
valece en el corazón, se explica la taquicardia encontrada en estos pacientes.

En modelos animales con mutaciones en el TR $\alpha$ no se produce el fenotipo de SRT, sino que, dependiendo del tipo de mutación, mueren al poco tiempo de nacer o presentan otros fenotipos como infertilidad, alteraciones en el metabolismo lipídico, en el crecimiento, en funciones cognitivas, etc. Esta puede ser la razón por la cual se han encontrado pocos pacientes con mutaciones en el TR $\alpha$. Estos pacientes caracterizados en los últimos años, presentan una serie de a compatibles con la distribución tisular del TR $\alpha$ en hueso, cerebro, intestino, corazón y músculo, tales como retraso de crecimiento con displasia esquelética que resulta en extremidades inferiores cortas y cabeza grande, retraso motriz y mental, bradicardia y reducción de la fuerza muscular.

Algunos individuos con RTH no presentaron mutación alguna del TR tanto $\alpha$ o $\beta$. El defecto podría deberse, por lo tanto, a alteraciones en los cofactores (correpresores-coactivadores) involucrados en el mecanismo de acción de hormonas tiroideas.

\section{Conferencia}

\section{Diagnóstico y tratamiento del hipopituitarismo}

\section{Karina Danilowicz}

$\mathrm{E}$ 1 hipopituitarismo resulta de la disminución de la secreción de una o más de las hormonas hipofisarias. Puede resultar de una afección primaria de la glándula hipofisaria o secundario a una disfunción hipotalámica. La falta total de la función pituitaria se denomina panhipopituitarismo. Si el déficit es de una o varias de las hormonas, nos encontramos frente a un hipopituitarismo parcial, mientras que el déficit de una hormona se denomina hipopituitarimo selectivo o aislado.

Las manifestaciones del hipopituitarismo son frecuentemente sutiles e inespecíficas, por lo que es frecuente el subdiagnóstico o el diagnóstico tardío. La incidencia se estima en 4,2 casos nuevos por año por 100.000 habitantes con una prevalencia de 45,5 por 100.000 .

El hipopituitarismo puede originarse por causas adquiridas o menos frecuentemente por causas genéticas. Las causas pueden dividirse en: defectos congénitos en el desarrollo de las células de la hipófisis anterior o en la función hipotalámica, enfermedades adquiridas hipotálamo-pituitarias o lesiones infundibulares. En la afección hipotálamo-pituitaria o infundibular, se destaca la patología tumoral, así como su tratamiento, ya sea la cirugía o la radioterapia. Los adenomas pituitarios constituyen la causa más frecuente de hipopituitarismo, y son la patología más común de la región selar. La radioterapia para el tratamiento de los adenomas hipofisarios se acompaña de hipopituitarismo en más del 50\% de los pacientes. En los últimos años se incluye al traumatismo encefalocraneano como otra entidad causante de hipopituitarismo.

En pacientes con cuadro de depresión, síndrome de impregnación o letargia, el diagnóstico de hipopituitarismo debe considerarse. La historia clínica cuidadosa con atención a los antecedentes, sumado al examen físico, ayudan al diagnóstico, que se confirma con las mediciones bioquímicas.

Las manifestaciones clínicas del hipopituitarismo dependerán, por un lado, de los signos y síntomas de masa ocupante, en los casos de patología tumoral o infiltrativa, sumado a los signos y síntomas derivados de cada uno de los déficits hormonales. En consecuencia, el hipopituitarismo es una condición altamen- te heterogénea en la que la presentación clínica dependerá de la enfermedad pituitaria subyacente, así como de su evolución, número de ejes afectados y la severidad del compromiso.

La confirmación del hipopituitarismo exige la medición de las hormonas periféricas con sus respectivas trofinas hipofisarias. La valoración bioquímica incluye en ocasiones tests dinámicos. Las mediciones hormonales basales consisten en la medición de cortisol sérico matinal, ACTH y cortisol libre en orina de 24 horas (CLU) para valorar el eje córticotropo. El eje tiroideo se evalúa con la medición de TSH y T4 libre. Para valorar el eje gonadal, testosterona total, LH, FSH en hombres, y LH, FSH, estradiol y progesterona en mujeres. Encontraremos frente a un hipopituitarismo un descenso en el nivel de la hormona de la glándula periférica (cortisol, T4 libre, testosterona, estradiol) junto con una concentración sérica normal pero inadecuada o disminuida de la respectiva trofina hipofisaria. Puede agregarse la medición de PRL que con frecuencia se hallará levemente elevada. Una aproximación al estudio de la reserva somatotrófica puede realizarse con la medición de IGF-1 (ajustado a edad).

En la valoración del paciente hipopituitario, el test más validado y reproducible es el test de hipoglucemia insulínica (ITT) que consiste en la inyección endovenosa de insulina regular humana $(0,05$ a 0,1 U/kg), midiendo glucosa, GH y cortisol. Los puntos de corte de normalidad se han fijado para el cortisol en $18,1 \mu \mathrm{g} / \mathrm{dl}$ y GH $3 \mathrm{mcg} / \mathrm{L}$ en adultos descartando, respectivamente, la deficiencia de ACTH y la deficiencia severa de GH. En la evaluación del eje somatotrófico, en el caso que esté contraindicada la ITT, puede recurrirse al test con glucagón 1 mg IM.

Para el diagnóstico del déficit corticotropo, si el cortisol matinal supera los $20 \mathrm{mcg} / \mathrm{dl}$ descarta la IA y si es menor de 3 $\mathrm{mcg} / \mathrm{dl}$ lo confirma. El test de estímulo con $250 \mathrm{mcg}$ de ACTH 1-24 mide la respuesta en cortisol al estímulo IM o EV, con un valor de normalidad mayor a 18. En una mujer posmenopáusica el diagnóstico del déficit gonadal es sencillo frente al hallazgo de gonadotrofinas bajas o indetectables. En mujeres jóvenes frente a la amenorrea debe descartarse el embarazo. La amenorrea con gonadotrofinas normales o bajas y bajos ni- 
veles de estradiol conducen al diagnóstico de hipogonadismo central. En los hombres el hipogonadismo se diagnostica por una concentración baja de testosterona con gonadotrofinas normales o bajas. El diagnóstico de la deficiencia tirotropa se realiza con un nivel sérico de TSH normal o bajo junto con un nivel sérico bajo de T4 libre. En ocasiones la TSH puede hallarse ligeramente elevada pero inadecuada para el descenso de las hormonas periféricas.

El tratamiento del hipopituitarismo es crónico. El objetivo es eliminar o minimizar los signos y síntomas de los déficits hormonales específicos. Las hormonas pituitarias ejercen influencias entre sí, de manera que en el reemplazo del hipopituitarismo hay que contemplar interacciones en la terapéutica hormonal.

El remplazo debe iniciarse, si es pertinente, con hidrocortisona 10-20 mg/día en el caso de un déficit de cortisol, explicando al paciente cuidadosamente las pautas de estrés.
El remplazo tirotrófico debe realizarse con levotiroxina 75-150 mcg por día $(1,6 \mathrm{mcg} / \mathrm{kg} /$ día $)$. El monitoreo debe realizarse con T4 libre, tratando de alcanzar concentraciones en el rango de la normalidad, en la mitad superior del rango de referencia. El remplazo androgénico en el hipogonadismo masculino mantiene los caracteres sexuales secundarios, mejora la calidad de vida, y previene la desmineralización ósea. El remplazo gonadal se lleva a cabo en las mujeres hasta la edad de la menopausia fisiológica. La administración de GHrh mejora algunos de los componentes del DGHA. El remplazo con GHrh se ajusta cada cuatro semanas según el valor de IGF-1 y la respuesta clínica. La dosis de inicio habitual es de 0,15-0,30 mg/día, en función de edad y sexo.

En general, la enfermedad pituitaria se vincula con alteración en la calidad de vida. La sustitución hormonal no reproduce fielmente la secreción del individuo sano. La titulación del remplazo tampoco es sencilla.

\title{
Conferencia
}

\section{Deficiencia combinada de hormonas hipofisiarias}

\author{
Karina Danilowicz
}

$\mathrm{L}$ as hormonas pituitarias son cruciales para el crecimiento y el desarrollo. La embriogénesis pituitaria es un proceso complejo que requiere de la acción coordinada de señales moleculares y factores de transcripción.

El hipopituitarismo puede originarse por causas adquiridas o menos frecuentemente por causas genéticas. Las causas pueden dividirse en: defectos congénitos en el desarrollo de las células de la hipófisis anterior o en la función hipotalámica, enfermedades adquiridas hipotálamo-pituitarias o lesiones infundibulares.

Debido a las alteraciones congénitas, se encuentran anomalías estructurales de la hipófisis como ausencia (aplasia), hipoplasia o presencia de tejidos hipofisarios ectópicos. Los factores de transcripción hipofisiarios están involucrados en la diferenciación de las líneas celulares de la adenohipófisis. El déficit combinado de hormonas hipofisiarias (CPHD) se define como la falta de producción de dos o más hormonas hipofisiarias, siendo esporádico en la mayoría de los casos. Diferentes genes están involucrados en la diferenciación de las células hipofisiarias y sus mutaciones son causa genética del CPHD pero con una baja frecuencia, siendo la mutación de $P R O P 1$ la más común.

Hesx1 es uno de los factores de transcripción más tempranos. Mutaciones en el gen HESX1, codificado en el cromosoma 3 y miembro de los genes homeobox, fueron identificadas en pacientes portadores del síndrome de displasia septo-óptica (DSO) con hipopituitarismo, neurohipófisis ectópica y diabetes insípida.

Los factores de transcripción de la familia LIM se expresan tempranamente. Los factores de transcripción LIM (LHX4,
LHX3, LHX2 o ISL1) son esenciales en la ontogenia pituitaria, y sus mutaciones originan CPHD, con anormalidades extrahipofisarias. Los defectos genéticos en LHX4 se acompañan de una alta variabilidad en las manifestaciones clínicas, aun en la misma familia, sin una clara correlación fenotipo-genotipo, con déficit de GH, TSH y ACTH, así como también anormalidades cerebelosas. La mutación en $L H X 3$ cursa con hipoplasia hipofisiaria anterior con déficit de $\mathrm{GH}$, prolactina, TSH y gonadotrofinas (LH/FSH), con preservación del eje corticotropo, junto con déficit auditivo y anormalidades esqueléticas.

En las formas de CPHD asociadas a mutaciones en PROP1 y POUF1F1 hay ausencia de anormalidades extrapituitarias. Se diagnostica en la infancia con retraso en el crecimiento por déficit somatotropo y/o hipotiroidismo clínico con bajos niveles séricos de PRL. Mutaciones en el factor de transcripción POUF1F1, codificado en el cromosoma 3, se acompañan de déficit somatotropo, tirotropo y prolactínico. En 30\% de los casos se halla la mutación R271W. Cuando la mutación es del factor PROP1, codificado en el cromosoma 5, se agrega el déficit gonadotropo, pudiendo agregar con el tiempo déficit corticotropo. Esta mutación es una de las más frecuentemente encontradas. La frecuencia de mutaciones en PROP1 varía en diferentes países, siendo más alta en Rusia, Europa del Este, Portugal y Brasil, con una frecuencia de hasta 11,2\%.

Mutaciones en $\mathrm{SHH}$ se han descrito en pacientes con holoprosencefalia, o fenotipos símil holoprosencefalia con anormalidades pituitarias y polidactilia. Mutaciones en GLI2 ocasionan hipopituitarismo congénito sin holoprosencefalia, con neurohipófisis ectópica. 
Entre los mecanismos más recientes se describe la mutación en el gen IGSF1 que codifica para una glucoproteína de la superfamilia de inmunoglobulinas de membrana. Su déficit origina hipotiroidismo central y macroorquidismo, con retraso puberal.

La proteína G acoplada al receptor 161 se expresa ampliamente en la hipófisis y el hipotálamo. Su mutación origina déficit de GH, hipoplasia hipofisiaria anterior y neurohipófisis ectópica.

El receptor nuclear translocador 2 aril hidrocarbonado (ARNT2) tiene un papel no muy claro en el desarrollo hipofi- siario. En el caso de mutaciones de transmisión autosómico recesivo la presentación clínica se caracteriza por diabetes insípida, déficit de ACTH, GH, LH/FSH, hipoplasia pituitaria anterior, neurohipófisis ectópica, hipoplasia de los lóbulos temporal y frontal, adelgazamiento del cuerpo calloso, retraso en la mielinización cerebral, frente prominente y retrognatia.

En las últimas décadas mucho se ha avanzado en el conocimiento de las causas genéticas del CPHD. No obstante, las frecuencias son bajas, siendo necesaria la identificación de nuevos genes candidatos.

\section{Conferencia}

\section{Melatonina, GH y trastornos metabólicos}

\author{
Hugo Fideleff
}

$\mathrm{L}$ a glándula pineal y su principal producto de síntesis, la melatonina, ha sido un tema relevante en la historia de la medicina. Las primeras "representaciones" de esta glándula forman parte de la religión hindú, ya que aparece como un tercer ojo en Shiva, quien junto a Brahma y Visnú forman parte de su trinidad sagrada.

La primera descripción histórica se le atribuye a Herófilo de Alejandría en el siglo III a C., pero fue Descartes quien consideró a la pineal como órgano clave y asiento del alma, dando pie a investigaciones científicas ulteriores y especulaciones filosóficas. Se le debe a Lerner, en 1958, el nombre de melatonina a la secreción de esta glándula, la cual reproducía los efectos de los extractos pineales y revertía las secuelas de la pinealectomia. Químicamente se trata de la N-acetil-metoxitriptamina y actúa como un transductor neuroendocrino de la información captada del medio ambiente vía la retina, pasando por un circuito en que están involucradas, entre otras estructuras, el tracto retino-hipotalámico, el núcleo supraquiasmático y el ganglio cervical.

La melatonina presenta un ritmo de secreción circadiano con bajas concentraciones durante el día y altas durante la noche, con un pico máximo que se alcanza alrededor de las 3 a.m. Su actividad es mayor durante la infancia y disminuye progresivamente en las siguientes décadas de la vida.

Contribuye de manera fundamental a la coordinación de los ritmos biológicos, desempeñando un papel clave en el ciclo luz-oscuridad y, en los últimos años, han surgido evidencias respecto a su participación en la modulación de la temperatura corporal, sus acciones metabólicas, efectos antiproliferativos, efectos antioxidantes, interrelación con el sistema inmune y el papel fundamental que juega en el ajuste estacional de la reproducción, maduración gonadal y regulación puberal en ciertas especies.

La melatonina influye sobre la producción energética y la composición corporal en mamíferos y ha sido demostrado, en ratas, el incremento de la grasa visceral con la edad y la conco- mitante disminución de la melatonina, la cual puede ser revertida con su administración diaria.

Nuestro grupo de trabajo demostró hace unos años que la excreción urinaria de la 6-sulfatoximelatonina (6-SM ), metabolito urinario predominante y representativo de la producción de melatonina, era mayor en varones púberes obesos que en los de peso normal no observándose este hallazgo en las niñas, lo que constituye un evidente dimorfismo sexual. Sin embargo, debe tenerse en cuenta que la melatonina tiende a ser mayor en las mujeres que en los varones durante el curso de la vida; además, hay una gran variabilidad interindividual y que la distribución diferente de la masa grasa entre varones y mujeres ya se comienza a detectar en los últimos años de la prepubertad. Por lo tanto, los niveles altos de 6-SM de las niñas y la diferencia entre los varones púberes obesos vs. los normopeso podría explicarse, en parte, por la distinta composición y distribución de la grasa puberal entre ambos sexos.

Con respecto a la relación entre hormona de crecimiento (GH) y melatonina, persisten aún datos poco claros. Teniendo en cuenta que la melatonina constituye un integrante fundamental del denominado "reloj biológico" relacionado con los ritmos circadianos y las alteraciones hormonales dependientes del sueño, y conociéndose que la GH tiene una secreción fisiológica predominantemente nocturna se plantean, entonces, una serie de interrogantes.

En estudios de nuestro grupo de trabajo en niños y adolescentes varones GHD y controles no hallamos diferencias en los valores diurnos de 6-SM. En ese mismo grupo, los niveles nocturnos totales y la diferencia noche-día mostraron que los pacientes tratados como no tratados tenían valores más bajos que los normales sin diferencia entre ellos. Esto podría explicarse, en parte, por las diferentes etiologías, edad de comienzo, duración de la deficiencia y tiempo de sustitución. También, en otro estudio efectuado en pacientes con síndrome de Prader Willi demostramos una clara inversión del ritmo de secreción de melatonina. 
Todos estos hallazgos contribuyen a incorporar nuevos conocimientos sobre los desórdenes cronobiológicos involucrados en la GHD y permiten especular sobre posibles mecanismos fisiopatológicos que afectan, además, calidad de vida, trastornos del sueño y funciones metabólicas.

Finalmente, además de la integración de la glándula pineal y la melatonina al sistema endocrino, se conocen actualmente la síntesis extrapineal de la misma, así como la relación entre melatonina y ciertos procesos vinculados al envejecimiento, cáncer, alteración del sistema inmunitario, actividad antioxidante, etc.

Podríamos concluir que el conocimiento de la intensa actividad bioquímica de la pineal y dado que su estructura "aloja" una serie de aminas biógenas tales como la serotonina, noradrenalina e histamina, múltiples sustancias peptidérgicas como vasopresina, VIP, NPY, somatostatina y hormonas (LH, FSH, TRH, ACTH y PRL) nos permite especular que esta hormona de la "oscuridad" arroja luz sobre nuestros conocimientos científicos.

\section{Conferencia}

\section{Etapa de transición: una visión crítica}

\section{Hugo Fideleff}

$\mathrm{E}$ la vida del ser humano se reconocen distintas etapas y cada una de ellas tiene características propias, tanto desde el punto de vista fisiológico como psicológico. Estas etapas han ido evolucionando desde los orígenes de la vida, y las modificaciones han tenido relación directa con numerosos factores socioambientales, étnicos, nutricionales, genéticos, etc. Clásicamente se ha reconocido una fase prenatal, neonatal, lactancia, infancia, niñez, pubertad, adolescencia, adultez y senectud. En los últimos años, al periodo que comienza hacia el fin de la pubertad y finaliza cuando se adquiere la maduración adulta completa, se le ha denominado "transición".

Esta fase dura aproximadamente 6 a 8 años y durante la misma se producen una serie de cambios cuanti y cualitativos en la esfera física y psíquica, caracterizados por la adquisición de la talla y composición corporal adulta, del pico de masa ósea, la obtención de una plena capacidad fértil y, finalmente, de las características psicosociales propias del adulto. Este periodo en la especie humana es prolongado y complejo y sería inapropiado considerarlo tanto como una extensión de la adolescencia, como del inicio de las primeras etapas de la adultez. En el área de la endocrinología pediátrica se plantean aspectos propios según la patología presente (déficit de hormona de crecimiento, síndrome de Turner, síndrome de Klinefelter, hiperplasia suprarrenal congénita, etc.) siendo el primero mencionado uno de los temas más conflictivos.

El crecimiento lineal y la adquisición de la talla final no significan el fin de la acción de la hormona de crecimiento (GH). Por el contrario, deben recordarse los efectos que la GH ejerce a lo largo de toda la vida del sujeto sobre el metabolismo, función y estructura cardiaca, hueso, composición corporal y calidad de vida. Ello significa que, ante la existencia de trastornos de esta hormona en la infancia, al llegar al periodo de transición debe ser reevaluado su perfil secretorio y profundizarse en el estudio de factores de riesgo cardiovascular, perfil lipídico, metabolismo óseo y calidad de vida (QoL).

Los adultos jóvenes con deficiencia de hormona de crecimiento (GHD) constituyen un grupo heterogéneo, que pueden presentar empeoramiento de su perfil metabólico, composi- ción corporal y QoL, con buena respuesta a la terapia de remplazo. Tal heterogeneidad podría ser parcialmente relacionada al momento de comienzo de la enfermedad, ya que hay adultos con GHD de inicio en la infancia (CO-GHD), y pacientes que desarrollaron la deficiencia en forma tardía durante la adolescencia o en la adultez. El tratamiento con GH tiene como objetivo principal, en la infancia, estimular el crecimiento lineal, para llegar a una talla final acorde con la talla blanco genética. También, en esta etapa de la vida, dicho tratamiento juega un papel importante en alcanzar y mantener la maduración somática, metabólica y la mineralización ósea. Por otra parte, en adultos con GHD (AO-GHD), ha sido descrita una disminución de la masa magra corporal, alteración del metabolismo lipídico, incremento del riesgo cardiovascular y alteración de la calidad de vida. Esto plantea que en los pacientes CO-GHD debe reevaluarse, una vez completada la etapa de crecimiento, si continúan siendo severamente insuficientes de GH, lo cual justificaría continuar con el tratamiento sustitutivo. Al respecto hay datos conflictivos y contradictorios sobre la necesidad de continuar con la misma durante la etapa de transición sin interrupción. La mayoría de los estudios sugieren que la continuación del tratamiento con hormona de crecimiento podría prevenir el comienzo de las alteraciones metabólicas y el deterioro de la composición corporal, mientras que el impacto del tratamiento sobre la calidad de vida y el bienestar psicológico es, aún, materia de controversia.

Finalmente, debe tenerse en cuenta que existe un grupo de pacientes que adquieren la insuficiencia de GH durante el periodo de transición. Por todo ello, se plantean una serie de interrogantes durante esta etapa:

1) Quiénes deben ser reevaluados

2) Cuándo reevaluar

3) Cómo reevaluar

Si se comprobara la persistencia del déficit de GH y se decidiera tratarlo, surgen otros nuevos interrogantes:

1) Porqué tratar con $\mathrm{GH}$

2) A quiénes tratar

3) Cómo tratar 
Estos aspectos conflictivos son, en gran parte, debidos a que el periodo de transición constituye una etapa sumamente dinámica por lo que podría considerarse en realidad, un "blanco móvil".

La necesidad de reevaluar se debe a que la "normalización" de la secreción de $\mathrm{GH}$, finalizado el periodo de crecimiento longitudinal, ha sido descrita hasta en un $44 \%$ de los pacientes con patología orgánica y/o deficiencia hipofisiaria múltiple y hasta en un $88 \%$ en pacientes con déficit aislado e idiopático de GH. Es importante consignar que el valor del pico de GH cuando se efectúa el diagnóstico de GHD en la etapa pediátrica, no predice el resultado de la reevaluación futura. También, debe tenerse en cuenta que la dinámica secretoria de GH es distinta en los niños en crecimiento, de aquellos pacientes que están alcanzando la talla final adulta y, por lo tanto, la evaluación en las dife- rentes edades tiene patrones específicos según los respectivos momentos evolutivos. Al igual que en otras etapas de la vida, los factores que contribuyen a las dificultades diagnósticas, son las distintas metodologías utilizadas para la dosificación de GH según los diferentes calibradores empleados, la heterogeneidad de la molécula, posibles interferencias con la proteína transportadora de hormona de crecimiento, las particulares especificidades para distintos epítopes de GH y anticuerpos, etc.

En conclusión, la profundización de los estudios y seguimientos de pacientes, no solo con GHD, sino también en todo el espectro de la patología endocrina, profundizando el monitoreo de marcadores metabólicos, factores de riesgo cardiovascular y de mineralización ósea acorde con las eventuales alteraciones genéticas presentes, permitirá adoptar conductas basadas en evidencias científicas validadas.

\title{
Conferencia
}

\section{Tiroides y fertilidad}

\author{
Marcos Abalovich
}

$\mathrm{S}$ e define infertilidad como la imposibilidad de concebir de una pareja luego de un año de búsqueda sin métodos anticonceptivos. Afecta $10 \%$ a $15 \%$ de la población representando la causa femenina aislada el $33 \%$.

La prevalencia de hipotiroidismo subclínico (HS) entre las mujeres infértiles es extraordinariamente variable, oscilando entre $0,7 \%$ y $46 \%$ de acuerdo con diversos trabajos. Las razones para gran variabilidad hay que buscarlas en las diferentes metodologías utilizadas para la medición de TSH, en los criterios con los que se define HS y en el empleo o no de la prueba de TRH.

Asimismo, la prevalencia de autoinmunidad tiroidea (AIT) en mujeres eutiroideas en edad reproductiva se ha estimado entre $15 \%$ y $20 \%$. La presencia de anticuerpos antitiroideos en estas mujeres puede condicionar el doble de riesgo de aborto que en aquellas sin anticuerpos. Del mismo modo, en mujeres con aborto recurrente se han hallado anticuerpos positivos más frecuentemente que en las que no tuvieron pérdida de embarazos. Se duda si las mujeres eutiroideas con AIT podrían tener un mínimo grado de hipotiroidismo subyacente o si el anticuerpo sería un mero marcador de un disturbio autoinmune más generalizado. Al respecto, se ha demostrado que las mujeres infértiles con AIT pueden tener TSH más altas, aunque dentro del rango normal, que aquellas sin anticuerpos. En estos casos, la prueba de TRH, muy poco empleada en la actualidad, puede ser útil para demostrar un leve grado de HS.

Es habitual que a una mujer en estudio por su fertilidad, se le indique la realización de una histerosalpingografía. Se ha demostrado que la sustancia yodada de contraste puede producir hipotiroidismo transitorio en el $18 \%$ de las mujeres que realizan el estudio, con una duración de hasta nueve meses en algunos de los casos.

Con respecto a mujeres que van a técnicas de reproducción asistida, diversos trabajos han demostrado que la presencia de anticuerpos antitiroideos no impide la posibilidad de embarazo al realizar los procedimientos pero aumenta el riesgo de aborto. En dichas técnicas debe tenerse en cuenta que la inyección de HCG para provocar ovulación puede originar ascenso en los niveles de TSH y disminución en los de T4 libre.

En lo que hace al tratamiento con levotiroxina en mujeres infértiles con HS, las Guías de ATA 2017 sugieren considerar la posibilidad de tratamiento cuando la búsqueda de embarazo sea "natural" pero dicho tratamiento debería ser obligado si va a técnicas de reproducción asistida. Esto se debe a que trabajos prospectivos y aleatorizados han demostrado que el porcentaje de ovocitos fertilizados y de RN vivos fue significativamente mayor y el porcentaje de abortos significativamente menor cuando las mujeres con HS estaban tratadas con LT4 al momento del procedimiento. El objetivo del tratamiento sería alcanzar un nivel de TSH menor de 2,5 mUI/L, aunque un nivel menor de 1,2 mUI/L sería preferible para tratar de evitar que los ascensos de TSH durante la inducción de ovulación o en caso de embarazar, hagan salir de rango a la hormona.

Es motivo de fuerte controversia si las mujeres eutiroideas con AIT, infértiles o abortadoras recurrentes, deberían ser tratadas con levotiroxina. Las Guías de ATA 2017 consideran que no hay evidencia suficiente para determinar si el tratamiento con levotiroxina mejora la fertilidad en dichas mujeres cuando buscan embarazarse en forma "natural" y, por lo tanto, no recomiendan tratamiento en esta situación.

En cambio, si las mujeres eutiroideas con anticuerpos positivos van a técnicas de reproducción asistida, podría considerarse la administración de bajas dosis (25 -50 mcg/día) de levotiroxina por su potencial beneficio sobre su mínimo riesgo, 
aunque no hay evidencia suficiente para determinar si la medicación mejorará el éxito en el logro de embarazos. La realización de la prueba de TRH, antes de indicar levotiroxina, podría ayudar a definir las pacientes con AIT que deberían ser tratadas tal como recomendamos en la Guía Argentina de FASEN.
No existen aún evidencias suficientes acerca de que el empleo de glucocorticoides o selenio podría mejorar el logro de embarazos en mujeres eutiroideas con anticuerpos positivos.

\section{Conferencia}

\section{Síndromes hereditarios de tumores hipofisarios}

\section{Moisés Mercado}

UIM en Endocrinología Experimental, Centro Médico Nacional Siglo XXI, IMSS, Ciudad de México, México.

$\mathrm{L}$ a mayoría de los adenomas hipofisarios son neoplasias epiteliales monoclonales benignas que ocurren de manera esporádica y no familiar. Si bien menos del 5\% de los adenomas hipofisarios ocurren en un contexto genético o sindrómico, es en estos casos en los que se conocen con razonable detalle los mecanismos oncogénicos que dan lugar al aumento en la proliferación celular y en algunos casos, a estados de hipersecreción hormonal. Los siguientes son los síndromes hereditarios que incluyen la presencia de adenomas hipofisarios:

- Neoplasia endocrina múltiple tipo 1 (NEM1): Los pacientes con NEM1 presentan tumores del páncreas endocrino, las paratiroides y la hipófisis. Este síndrome está causado por mutaciones activadoras del gen de la menina que codifica una proteína nuclear que tiene funciones supresoras de tumores. Aproximadamente $60 \%$ de los pacientes cursan con adenomas hipofisarios, siendo los prolactinomas los más frecuentes, seguidos por los tumores productores de GH y, posteriormente, los de ACTH; cerca del 10\% de estas lesiones son plurihormonales. Los adenomas hipofisarios que ocurren en el contexto de la NEM1 son generalmente de mayor tamaño y muestran un comportamiento biológico más agresivo que sus contrapartes esporádicas, además de que afectan a pacientes más jóvenes. Este síndrome se hereda de manera autosómica recesiva.

- Complejo de Carney: Se debe a mutaciones inactivadoras del gen que codifica la subunidad reguladora $1-\alpha$ de la proteína cinasa A (gen CNC1). Consiste en hiperplasia suprarrenal micronodular pigmentada, asociada a mixomas auriculares, Shcwanomas melanóticos, lentigines y hasta en un 30\%, adenomas hipofisarios, más frecuentemente productores de GH y en menor medida prolactinomas.

- Neoplasia endocrina múltiple tipo 4 (NEM4): Consiste de los mismos componentes de la NEM1 pero sin alteraciones moleculares en el gen de la menina. En estos casos se han descrito mutaciones inactivadoras del gen $C D K N 1 B$ que codifica el inhibidor de cinasas dependiente de ciclinas conocido como p27.

- Síndrome de adenoma hipofisario familiar aislado: Conocido por sus siglas en inglés, FIPA, ocurre en familias en las que existen por lo menos dos individuos con adenomas hipofisarios sin otros componentes clínicos. El adenoma hipofisario más frecuentemente encontrado es el somatotropinoma, seguido por el prolactinoma y los adenomas clínicamente no funcionantes. Por lo menos el $20 \%$ de estos casos se debe a mutaciones germinales activadoras del gen que codifica la proteína de interacción con el receptor de hidrocarburos arilados (AIP), el cual es considerado un gen supresor de tumores. Con una herencia autosómica recesiva de penetrancia variable, los pacientes con este síndrome tienden a ser más jóvenes, con adenomas más grandes e invasivos, particularmente resistentes al tratamiento con análogos de somatostatina y frecuentemente asociados a hiperprolactiemia. En poblaciones con acromegalia-gigantismo aparentemente esporádico de inicio antes de los 30 años, podemos encontrar mutaciones del gen $A I P$, tanto somáticas (en el tumor mismo) como en la línea germinal en 4\%-10\% de los casos.

- Acrogigantismo ligado al cromosoma X: Son pacientes con adenomas productores de GH de aparición en la infancia temprana, asociados a microduplicaciones del cromosoma Xq26,3, que involucran al gen que codifica al receptor huérfano acoplado a proteínas $\mathrm{G}$, conocido como GPR101.

- Síndrome de McCune-Albright: Aunque no es un síndrome hereditario, se debe a mutaciones poscigóticas del oncogén GNAS1 y se caracteriza por fibrosis poliostótica, manchas café con leche y diversos estados de hiperfunción hormonal, de los cuales el más frecuente es la pubertad precoz pero también incluye el desarrollo de hiperplasia y adenomas hipofisarios. La línea celular hipofisaria más frecuentemente involucrada es el somatotropo, seguido por el lactotropo y el corticotropo. 


\section{Conferencia}

\section{Impacto metabólico en la fertilidad del varón}

Roald Gómez Pérez

Profesor Titular, Universidad de los Andes. Mérida, Venezuela.

$\mathrm{E}$ síndrome metabólico (SM) es una condición fisiopatológica caracterizada por resistencia a la insulina, lo cual favorece un conjunto de manifestaciones clínicas, como la dislipidemia, la hipertensión arterial, la diabetes y la obesidad central. La incidencia del mismo a nivel mundial se estima alrededor de un 30\%. En Latinoamérica existen algunos reportes poblacionales, en términos generales puede afirmarse que una de cada tres o cuatro personas mayores de 20 años, cumple criterios para diagnóstico de SM, según cual sea la definición empleada (IDF, ATP III, ALAD), en Venezuela en varios estudios se ha estimado su frecuencia entre $25 \%-30 \%$, la cual ha ido en aumento en los últimos años. La relación del síndrome metabólico y la infertilidad femenina está muy bien descrita; sin embargo, la relación de éste con la infertilidad masculina se mantiene en controversia. Si bien es cierto que una de las células más afectadas por el estrés oxidativo y el estado de inflamación en el organismo es el espermatozoide, son contradictorios los estudios en relación al efecto directo del SM sobre la fertilidad masculina.

Analicemos uno a uno los componentes de este síndrome para tratar de aclarar el efecto que ejercen sobre la vitalidad y calidad espermática.

En primer lugar la hipertensión arterial: hasta ahora, no existen hallazgos claros de su intervención en la esfera de la fertilidad masculina, considerar un daño testicular como efecto de la hipertensión arterial, hasta ahora no está bien definido. Sin embargo, no podemos obviar su efecto directo sobre el lecho vascular del pene y su importancia en la incidencia de la disfunción eréctil. Las dislipidemias, otro elemento importante del SM, principalmente la hipertrigliceridemia, juega un papel importante en el estrés oxidativo del microambiente testicular, condicionando una afectación a la integridad de membrana de los espermatozoides evento que compromete la motilidad y calidad espermática. Estudios en roedores sometidos a dietas ricas en grasas han demostrado compromiso de los parámetros clásicos del espermograma como también de la integridad de la cromatina y afectación de la fragmentación del ADN espermático. E inversamente, grupos experimentales tratados con drogas hipolipemiantes luego de dietas ricas en colesterol, demuestran una mejoría de las características de los espermatozoides con mejoría de la fertilidad.

La obesidad que día a día engloba a un mayor número de individuos en nuestra población, ejerce un efecto directo sobre la calidad espermática y la fertilidad masculina, varios de los mecanismos involucrados son el efecto de la misma sobre la disfunción del eje hipotálamo-hipófisis-testículo, varios estudios en las últimas décadas han demostrado cómo la obesidad mórbida afecta la secreción de las gonadotrópicas, además se correlaciona de una manera negativa con los niveles de testosterona total, libre y SGBH, y de manera positiva con niveles de estrógenos que bloquean la secreción de GnRh y las gonadotropinas. Otros mecanismos involucrados es el efecto que cumple la obesidad sobre el umbral inflamatorio, favoreciendo interleucinas y citocinas, las cuales intervienen el estado inflamatorio y el estrés oxidativo, conllevando a la peroxidación de lípidos poliinsaturados de la membrana del espermatozoide, esto lleva a un defecto de la movilidad espermática y favorece la fragmentación de ADN. Los espermatozoides con mayor daño del ADN y de la membrana activan todos los mecanismos enzimáticos para la apoptosis celular; sin embargo, algunos espermatozoides con daño en el ADN pueden fecundar, y llevar así afectaciones o mutaciones puntuales que se traducen en enfermedades en el producto, desencadenando abortos tempranos o desarrollo de cáncer u alteraciones metabólicas. El acúmulo de grasa en la región inguinal también cumple un efecto deletéreo en la fertilidad del varón, la formación de lipomas a este nivel desplaza el cordón espermático y cumple un efecto obstructivo, tanto para el conducto deferente como para el sistema vascular. Favoreciendo un aumento en la estasis venosa y de la temperatura de la gónada, efectos que comprometen el funcionamiento adecuado del microambiente testicular. Así, pudiéramos considerar que la obesidad por estos tres elementos, disfunción del eje gonadal, activación del estrés oxidativo y un efecto mecánico obstructivo de la grasa en el cordón inguinal contribuye en la subfertilidad del varón.

El estado de prediabetes o diabetes, otro componente del SM, cada día se involucra más en la subfertilidad masculina. Sumado a la neuropatía y vasculopatía que condiciona disfunción eréctil y eyaculación retrógrada en algunos pacientes, estudios en roedores con diabetes inducida han demostrado una afectación directa en la estructura normal de los túbulos seminíferos y del espacio intersticial con afectación importante de las células de Sertoli y de Leydig que conlleva a un deletéreo en la maduración de las células espermáticas. Niveles altos de peroxidación lipídica, ROS, especies de oxígeno reactivas y niveles bajos de actividad antioxidante de la catalasa, glutatión reductasa, glutatión peroxidasa, y superóxido dismutasa han sido encontrados en fracciones mitocondriales y citosólicas de testículos de ratas diabéticas tratadas con STZ.

El efecto más importante de los componentes del SM sobre la calidad espermática radica en el estrés oxidativo y la peroxidación de los lípidos poliinsaturados de la membrana del espermatozoide, lo cual lo pudiéramos describir en dos fases, una primera fase donde ocurre un daño directo sobre la membrana espermática, condicionando espermatozoides alterados, con retención de citoplasma residual, alto contenido de núcleo histonas y con una pobre protaminación del ADN, los cuales los hacen altamente susceptibles a la apoptosis, y 
en una segunda fase donde hay una afectación de la fragmentación del ADN y modificación del material genético condicionado por mutaciones puntuales. Estas mutaciones pudieran afectar directamente la fusión óvulo-espermatozoide, desencadenar abortos y en última instancia enfermedades en el producto, como cáncer, afectaciones metabólicas futuras o afectaciones neurológicas. Si bien es cierto, no existen estudios poblacionales importantes que demuestren la afectación directa del SM sobre la fertilidad masculina y los parámetros espermáticos establecidos, hay evidencia clara que la carga genómica del espermatozoide está altamente afectada por cada uno de los componentes clínicos del SM.

\section{Conferencia}

\section{Tratamiento del exoftalmos}

\section{Alicia Gauna}

$\mathrm{L}$ a oftalmopatía de Graves (OG) es una enfermedad autoinmune caracterizada por una inflamación de los tejidos retrobulbares con acumulación de glucosaminoglicanos (moléculas hidrofílicas) secretados por los fibroblastos activados, aumento del tejido adiposo e infiltración linfocitaria en los músculos. Esto conlleva a un aumento de volumen del tejido conectivo orbitario y de los músculos extraoculares y la generación de exoftalmos. La incidencia anual es baja (3-16/100.000 habitantes según se trate de mujeres u hombres respectivamente). Más del $90 \%$ de los pacientes con enfermedad de Graves presentan alteraciones en la resonancia o tomografía de órbita, pero la oftalmopatía clínica es evidenciable en el 30\% al 50\% de los pacientes. La disfunción tiroidea -fundamentalmente hipertiroidismo- acompaña en más del $90 \%$ a la oftalmopatía, y dicho hipertiroidismo precede con frecuencia a la manifestación ocular en semanas o meses. Por lo tanto, es frecuente que el endocrinólogo pueda ser el primer especialista en contacto con el paciente y quien determina el grado de urgencia de la evaluación oftalmológica. Se trata de una enfermedad compleja con gran compromiso de la calidad de vida y que requiere de un equipo multidisciplinario para su tratamiento y es necesario un rol bien definido de la participación del endocrinólogo.

El primer tratamiento de la oftalmopatía es la prevención de su expresión clínica. En otras palabras, ¿cuáles son los factores de riesgo que condicionan su manifestación en el 30\% a 50\% de los enfermos de Graves? Son conocidos, el sexo masculino, el tabaquismo, la disfunción tiroidea, sequedad ocular y el tratamiento del hipertiroidismo con radioyodo. En nuestra experiencia, el tabaquismo y altos valores de TRAb quintuplicaron y casi triplicaron, respectivamente, el riesgo de oftalmopatía. Por lo tanto, un tratamiento antitabáquico y normalizar la función tiroidea son mandatorios. En cuanto al tratamiento del hipertiroidismo, el metimazol o la cirugía no implican un mayor riesgo para la oftalmopatía. A diferencia de éstos, el tratamiento con radioyodo puede asociarse con un mayor riesgo de la oftalmopatía. Con base en estos datos, si la oftalmopatía es activa,ya sea leve con factores de riesgo, o moderada-severa, debe asociarse la corticoterapia al tratamiento con radioyodo con el fin de evitar su agravamiento, como así también evitar el hipotiroidismo posradioyodo e implementar tempranamente la sustitución con hormona tiroidea.

Ante un paciente que manifiesta una oftalmopatía clínica es fundamental establecer si la misma es activa o no y el grado de severidad, porque de estos dos parámetros va a depender el tratamiento que se establezca. Las oftalmopatías no activas se tratan quirúrgicamente, si la severidad lo amerita, (descompresión de la órbita, cirugía de párpados o músculos); en cambio las oftalmopatías activas requieren inmunomoduladores o inmunosupresores. Es fundamental en una oftalmopatía activa prevenir su progresión y para ello es relevante conocer los factores relacionados con la severidad y la actividad. En nuestra experiencia, además del sexo masculino y la mayor edad, los valores más bajos de vitamina D y más elevados de IGF1 se asociaron con una mayor severidad.

La oftalmopatía activa leve se trata con medidas de sostén (lágrimas, protección de exposición al sol y otros agresores externos) y puede asociarse selenio. Si es moderada-severa y/o severa, el tratamiento de elección es la corticoterapia endovenosa, por la mejor tasa de respuesta y menos efectos colaterales. Nosotros utilizamos el esquema de Kahaly, con una tasa de respuesta del $75 \%$, similar a la referida en la bibliografía. En la OG severa con pérdida de visión, el esquema que empleamos es un gramo por día durante tres días consecutivos. Es de alto interés contar con marcadores para diferenciar respondedores de ese $25 \%$ no respondedor a la corticoterapia endovenosa. En tal sentido, menores valores de TRAb, el no deterioro de la oftalmopatía a las seis semanas de tratamiento y valores altos de la relación recto inferior/grasa $(>1,42)$ y del Exoftalmos $(>20,78)$ son referidos como marcadores de una respuesta positiva. En los pacientes no respondedores es necesario recurrir a segundos tratamientos como otro curso de corticoterapia endovenosa o radioterapia implementada en asociación con corticoides. Otra opción es el rituximab, con resultados controvertidos. Referencias en el último tiempo sobre tratamientos con micofelonato, teprotumumab y tocilizumab son promisorias.

La asociación de azatioprina a la corticoterapia para prolongar su efecto, un segundo curso de GC EV con o sin radioterapia asociada o la descompresión en los casos de oftalmopatías severas con riesgo de pérdida de la visión, son los tratamientos de segunda línea en nuestro servicio.

En síntesis, el tratamiento de la oftalmopatía de Graves requiere un equipo multidisciplinario, con papeles definidos y en el cual el endocrinólogo debe desempeñar una conducta activa, tanto en la prevención como en el diagnóstico y tratamiento. El tratamiento de primera línea en la oftalmopatía moderada a severa y en la severa con riesgo de pérdida de la visión son los glucocorticoides endovenosos. 


\title{
Conferencia
}

\section{Terapias orientadas a la lesión metastásica en carcinoma diferenciado de tiroides}

\author{
Inés Califano
}

Médica Especialista en Endocrinología, Instituto de Oncología AH Roffo, Universidad de Buenos Aires, Argentina.

Aproximadamente $30 \%$ de los pacientes con carcinoma diferenciado de tiroides (CDT) experimentan recurrencias estructurales de la enfermedad, la mayoría localizadas en territorios locorregionales. Las metástasis a distancia ocurren en $10 \%$ de los casos y comprometen pulmones, hueso y con menor frecuencia otros órganos.

Las terapias sistémicas en CDT incluyen el ${ }^{131} \mathrm{I}$ y, en los pacientes yodorrefractarios progresivos y sintomáticos, los inhibidores múltiples de tirosina cinasa (ITK). No obstante, solo un tercio de los pacientes ávidos por ${ }^{131}$ I tienen respuestas completas, mientras que en los casos de enfermedad yodorefractaria, los ITK pueden lograr estabilización o respuestas parciales.

Los pacientes con CDT y enfermedad avanzada pueden presentar sobrevida prolongada, no obstante, habitualmente existe morbilidad secundaria a las lesiones.

Los tratamientos locales tienen como objetivo controlar los síntomas y mejorar la calidad de vida del paciente. Estas intervenciones raramente son curativas, no obstante, pueden enlentecer la progresión de la enfermedad. Pueden utilizarse en combinación con las terapias sistémicas y deben ser consideradas al planear la estrategia terapéutica, principalmente en pacientes con enfermedad oligometastásica, sintomática o inminentemente complicable, en especial en casos de enfermedad yodorrefractaria.

De acuerdo con la localización y características de las metástasis, existen múltiples estrategias disponibles.

La enfermedad locorregional es la causa de muerte de hasta 35\% de los pacientes con CDT. Si bien la reintervención quirúrgica se considera el gold standard, las cirugías sucesivas presentan un riesgo elevado de complicaciones, mientras que la probabilidad de lograr remisión oscila entre 13\%$67 \%$. Otras opciones terapéuticas incluyen la radioterapia externa (RTE), la inyección percutánea de etanol (PEI) y la ablación por radiofrecuencia (RFA) de las lesiones. El control local esperable con estas estrategias es de entre 60\%-90\%.

La RTE debe considerarse para el tratamiento de restos tumorales macroscópicos yodorrefractarios irresecables, en pacientes con edad avanzada. Las técnicas de radioterapia de intensidad modulada son las que se prefieren, por su menor toxicidad. La PEI es útil para el manejo de lesiones de reducido volumen, localizadas preferentemente en el compartimiento lateral cervical, en pacientes que tuvieron previamente linfadenectomía. La RFA también se emplea en pacientes ya operados, con la ventaja de ser efectiva en lesiones de mayor tamaño (hasta $5 \mathrm{~cm}$ ), pero con mayor riesgo de complicaciones (quemaduras y lesiones de nervios por injuria térmica) y costos más elevados.

Las metástasis pulmonares suelen ser múltiples, difusas y milimétricas, por lo que no se consideran candidatas ideales para las terapias orientadas a las lesiones. Sin embargo, los casos seleccionados de lesiones periféricas y macronodulares, pueden ser candidatos a cirugía, RTE y/o RFA. Si bien la RFA es menos invasiva que los procedimientos quirúrgicos, la frecuencia de complicaciones es de hasta 39\% (infecciones, neumotórax).

Las metástasis óseas son sintomáticas en más de 70\% de los pacientes, ocasionando dolor, fracturas patológicas y/o síntomas neurológicos. Característicamente son lesiones refractarias al ${ }^{131} \mathrm{I}$. Las terapias dirigidas a las lesiones óseas incluyen la cirugía, RTE, procedimientos percutáneos (que incluyen RFA, crioablación y cementoplastia) y agentes antiresortivos (bifosfonatos endovenosos y denosumab).

Las terapias percutáneas se recomiendan en lesiones sintomáticas o inestables; la mejoría sintomática se observa en más de $50 \%$ de los casos y es posible lograr control local en aproximadamente la mitad de los pacientes.

La embolización de las metástasis óseas se recomienda previamente a la cirugía y reduce la vascularización de la lesión y el riesgo de sangrado intraquirúrgico; asimismo puede ser una técnica empleada en forma aislada en el manejo de los síntomas.

Las metástasis en sistema nervioso central ocurren hasta en $20 \%$ de los pacientes con CDT avanzado. Si bien el pronóstico es desfavorable, el tratamiento quirúrgico y/o la RTE estereotáctica mejoran la sobrevida y deben considerarse como primera línea de tratamiento. La cirugía es el tratamiento de elección siempre que sea posible. Se indica en casos de existir no más de dos lesiones cerebrales, con enfermedad controlada en otros territorios, únicas y en pacientes en buen estado general.

En conclusión, en el enfoque del paciente con CDT avanzado las terapias dirigidas a las lesiones son opciones que deben tenerse en cuenta más allá del uso de tratamientos sistémicos. En el diseño de la estrategia terapéutica deben considerarse factores del paciente, de la enfermedad, los recursos disponibles y la experiencia de cada equipo multidisciplinario tratante. 


\title{
Conferencia
}

\section{Cirugía bariátrica y metabólica}

\author{
César Ernesto Guevara Pérez
}

Presidente ACOCIB 2014-2018.

La cirugía bariátrica y metabólica se define como el conjunto de procedimientos quirúrgicos diseñados con la intención de perder peso y mejorar las enfermedades asociadas. Dichos procedimientos quirúrgicos se han enfocado en modificar anatómicamente el tracto digestivo con el objetivo de producir restricción a nivel del estómago y disminución en la absorción de calorías a nivel del intestino delgado lo que conlleva una serie de cambios entero-hormonales con afección de diferentes órganos blanco y del hipotálamo.

Las indicaciones actuales para recomendar una cirugía bariátrica y metabólica incluyen:

- Índice de Masa Corporal mayor de $40 \mathrm{~kg} / \mathrm{m}^{2}$ con o sin comorbilidades

- Índice de Masa Corporal entre 35 a $40 \mathrm{~kg} / \mathrm{m}^{2}$ con comorbilidades que sean susceptibles de mejorar luego de la cirugía.

- Índice de Masa Corporal entre 30 a $35 \mathrm{~kg} / \mathrm{m}^{2}$ con comorbilidades metabólicas, especialmente con diabetes mellitus tipo 2.

La cirugía bariátrica y metabólica ha evolucionado durante 60 años desde procedimientos puramente malabsortivos a técnicas mixtas que incluyen restricción gástrica y malabsorción intestinal. De la misma manera el desarrollo de tecnologías mínimamente invasivas ha permitido disminuir el impacto quirúrgico mejorando los resultados en el paciente.

Clásicamente, la cirugía bariátrica y metabólica se define, de acuerdo con su mecanismo primario de acción, en tres grupos principales:

- Procedimientos malabsortivos:

- Derivación biliopancreática (BPD)

- Switch duodenal (DS)

- Derivación duodeno-ileal de una anastomosis (SADI-S)

- Procedimientos mixtos:

- Bypass gástrico en Y de Roux (RYGB).

- Bypass gástrico de una anastomosis (minibypassBAGUA).

- Procedimientos restrictivos:

- Manga gástrica.

- Banda gástrica ajustable (BGA) (en desuso en Colombia y muchas partes del mundo)

Las cirugías más practicadas actualmente a nivel mundial son:

\section{Gastrectomía en manga por laparoscopia}

Es un procedimiento restrictivo caracterizado por una reducción importante de la capacidad gástrica, acompañado de la disminución en la producción de la hormona orexigénica lla- mada ghrelina, aumento del péptido similar al glucagón tipo 1 (GLP-1) y del péptido YY (PYY). Debido al vaciamiento rápido que puede presentarse, puede observarse también la presencia de síndrome de dumping temprano o tardío.

\section{Consideraciones técnicas}

La técnica debe incluir la disección de todo el epiplón de la curvatura mayor y resección lineal con sutura mecánica a partir de los 2 a $5 \mathrm{~cm}$ del píloro hasta el fondo gástrico, dejando una pequeña porción del mismo para no acercarse tanto o comprometer el esófago. Otro detalle técnico a tener en cuenta en la resección gástrica es no acercarse o presionar el dispositivo de sutura mecánica a la incisura angular, que es el sitio con mayor posibilidad de estenosis. Se deberá calibrar la resección gástrica con una bujía que pueda variar su diámetro (32-48 F), pero teniendo en cuenta que las más pequeñas podrían estar más relacionadas con complicaciones de fístulas y estenosis; de la misma manera, las de diámetro muy grande podrían estar relacionadas con malos resultados en la pérdida de peso. No hay consenso de si debe hacerse con sutura invaginante o transfixiante. Algunos grupos recomiendan la epiploplastia fúndica como medida de reforzamiento por ser el área más crítica con respecto a la formación de fístulas.

\section{Resultados}

Se ha reportado disminución en el peso de hasta $83 \%$ en los primeros tres años cuando se realiza gastrectomía en manga como primera opción en cirugía bariátrica, con una pérdida promedio del peso inicial de $61 \%$.

\section{Bypass gástrico por laparoscopia Consideraciones técnicas}

Se realiza una división (segmentación) del estómago con el fin de crear una pequeña bolsa gástrica proximal de alrededor de $60 \mathrm{ml}$. Es importante tener en cuenta que las bolsas gástricas más pequeñas se asocian con mayor pérdida de peso. Se continúa con una reconstrucción en Y de Roux conformando así el asa alimentaria, el asa biliopancreática y el asa común. Para realizar la reconstrucción en Y de Roux, el yeyuno se divide a unos 60-150 cm por debajo del ligamento de Treitz y el segmento distal se lleva al reservorio gástrico y anastomosado al mismo creando una anastomosis estrecha de 1,5-1,8 cm. El segmento proximal del intestino (asa biliopancreática) se anastomosa a 75-150 cm distal de la gastroyeyunostomía.

Diversos autores han cuestionado la distancia a la cual debe estar el asa biliopancreática, pero los resultados no muestran un mayor beneficio a más de $150 \mathrm{~cm}$ en pacientes con IMC $<50 \mathrm{~kg} / \mathrm{m}^{2}$; sin embargo, en pacientes con IMC $>50$ se evidenció mayor pérdida de peso con distancias más largas, pero asociado con mayor deficiencia nutricional. 


\section{Resultados}

La pérdida de peso en los pacientes llevados a bypass gástrico está entre el 60\%-80\% a 10 años con mejoría de las comorbilidades secundarias a la obesidad en más del $75 \%$ de los casos, demostrando un gran impacto en pacientes con DM2.

Los estudios han demostrado que los procedimientos bariátricos son efectivos para controlar enfermedades relacionadas con la obesidad en las siguientes tasas:

- Diabetes mellitus tipo 2: resolución o mejoría 86\%

- Dislipidemia: resolución o mejoría 70\%

- Hipertensión arterial: resolución o mejoría 78\%

- Apnea del sueño: $85 \%$

\section{Conclusión}

La cirugía bariátrica y metabólica es un procedimiento altamente efectivo para controlar el exceso de peso y sus enfermedades asociadas. Su práctica se ha extendido mundialmente lo que ha permitido obtener con mayor certeza resultados a mediano y largo plazo que permiten actualmente recomendarla en pacientes con menores grados de obesidad. Lo más importante que debe tener en cuenta un paciente o médico que recomienda una cirugía bariátrica y metabólica es que debe buscar grupos multidisciplinarios que integren profesionales de medicina, nutrición y psicología para lograr resultados mejores y a más largo plazo.

\section{Conferencia}

\section{Endocrine disrupting chemicals, estrogen and epigenetics}

\section{Jon Entine}

$\mathrm{E}$ ndocrine disruptor is a term used to describe natural or synthetic chemicals that modify our endocrine system--the collection of glands in our body that secrete hormones. From birth control drugs to certain foods like soy, tea and wine to pesticides, these chemicals are key ingredients in substances that enhance our everyday lives.

It's been hypothesized that chronic exposure even to small amounts of an environmental toxicant (which is often lipophilic and accumulates in fatty tissues) might be harmful, especially during high-risk windows of susceptibility, such as fetal development or early childhood.

It's also debated whether these chemicals can result in modifications of the epigenome. The term epigenetics encompasses alterations in the transcriptional potential of a cell that are not necessarily heritable as well as heritable changes.

The science behind how these chemicals work in humans remains unclear, as most of the research has been based on association studies in humans or on rodents exposed to doses not commonly encountered in everyday life. Because of their ubiquity, it is important to ensure that we understand the effects these chemicals may have on human health, positive and negative.

An example of an endocrine disruptor with positive effects is resveratrol, the compound in tannin in red wines that is said to be an antioxidant and an anticancer agent. Certain sex-steroid hormones, such as estradiol, can enhance memory function. They both modify our 'natural' estrogenic system and other hormone receptors.

There are two classes of EDCs. One type persists in the water table and accumulates in fatty tissues. Many pesticides are persistent; even a very small amount can accumulate in fatty tissues and be released gradually.
Other chemicals are not as persistent, such as bisphenol A, used to line metal cans or enhance the utility of plastic. It is oxidized in the liver within hours, conjugated and eliminated in the urine. But advanced monitoring devices can now find trace amounts of chemicals in urine or blood as low as parts per quadrillion, well below any known effect, spurring concerns.

Environmental groups, trial lawyers and some scientists embrace a theory that exposure to even non-persistent chemicals at low doses can induce harmful non-monotonic effects and alter the epigenome. BPA, they claim, is part of a rogue's gallery of chemicals that includes the common weed killers atrazine and glyphosate, plasticizer phthalates, dichlorobenzene used in mothballs and chemicals used to produce resins and detergents.

Some animal studies suggest that environmental exposure during pregnancy and early development might modify epigenomes and induce, trans-generationally, everything from cancer to obesity, retarded neurological development, asthma, autism, diabetes, cardiovascular disease, infertility and other sexual development disorders.

These concerns have been echoed by Linda Birnbaum, director of the National Institute of Environmental Sciences. In the NIEHS-published journal Environmental Health Perspectives, Birnbaum has argued that "it is time to start the conversation" about incorporating low doses and non-monotonic relationships into regulatory decisions.

Many scientists disagree with this perspective. While there is evidence that EDC exposure in utero or during sensitive periods of early development can perturb epigenetic programming, these changes do not necessarily permanently alter the epigentoype and are not necessarily predictive of long-term adverse outcomes. 
The European Food Safety Authority, a joint UN Food and Agriculture Organization/WHO expert panel on BPA, and an Advisory Committee of the German Society of Toxicology independently have concluded that BPA does not pose serious neurological dangers or cause cancer, and has modest but not necessarily harmful endocrine effects.

In February 2018, the US Food and Drug Administration released a two-year draft study by the National Toxicology Program. It looked at the effects of different doses of BPA, evaluating chronic and early-life exposure in different groups of rodents. The FDA reaffirmed its earlier evaluation of 300 scientific studies, which concluded that BPA is safe for consumers.

The doses ranged from low doses that would be comparable to typical human exposures, to doses that vastly exceed human exposures. A variety of endpoints were evaluated including growth, weight and tumor development. Overall, the NTP found 'minimal effects' for the BPA-dosed groups of rodents. Our initial review supports our determination that currently authorized uses of BPA continue to be safe for consumers.

Richard Sharpe, head of the Centre for Reproductive Biology at the Medical Research Institute in Edinburgh and one of the originators of the "environmental estrogen hypothesis" in the 1990s, changed his views in the face of the accumulating evidence. He outlined his revised perspective in Toxicological Sciences, in an article titled "Is It Time to End Concerns over the Estrogenic Effects of Bisphenol A?"

Sharpe believes that confirmation bias underlies the claim that BPA and other chemicals pose dangers: "I ended up disproving my own hypothesis/ ideas on the potential impact of environmental oestrogens on reproductive disorders early on in the EDC saga ... Plus, I was lucky that the question that drove me was 'what causes these disorders?' not 'how do EDCs cause these disorders'? Such a simple difference, but it takes your thought processes in a very different direction."

Nonetheless, persistent fear about possible adverse impacts, even in the absence of definitive evidence, has led to calls for precautionary regulation of EDCs, particularly in Europe. Government agencies have never required knowledge of a chemicals' mechanism of action before taking steps to regulate it. Many chemicals alleged to be endocrine disruptors, such as DDT and its metabolites, PCBs, dioxins, brominated flame retardants, organophosphates, etc. have already been either phased out or voluntarily withdrawn from consumer markets.

In sum, mechanistic links between EDC-induced epigenetic changes and phenotypic endpoints remain murky, but these chemicals are ripe for more research, considering the enormous potential health consequences.

\section{Conferencia}

\section{Insuficiencia renal y osteoporosis}

\section{Salomón Jasqui}

$\mathrm{L}$ os riñones son órganos sumamente relevantes ya que participan en diversas funciones cruciales para el mantenimiento homeostático: éstas comprenden desde la filtración de sustancias hasta la producción de eritropoyetina.

Existe una estrecha relación entre el funcionamiento renal y el metabolismo óseo, debido a que la hormona paratiroidea actúa a nivel renal promoviendo la reabsorción tubular de calcio y excreción de fosfatos. Por otro lado la vitamina D, importante en la absorción intestinal de calcio y formación de hueso, completa su activación en el riñón al ser hidroxilada por segunda vez.

Es por ello que la función renal normal se une a otros factores como dieta, ejercicio, edad y hormonas para promover la salud y calidad ósea. Sin embargo, cuando los riñones comienzan a fallar se presenta un síndrome clínico sistémico caracterizado por alteraciones del metabolismo óseo mineral detectable mediante anomalías de laboratorio, como alteraciones en los niveles de calcio sérico, vitamina $\mathrm{D}$, hormona paratiroidea y fósforo sérico.

Lo anterior se traduce en anormalidades en el recambio óseo, volumen de mineralización, crecimiento lineal y fuerza del hueso así como calcificación de tejidos blandos y vascula- res debido a la hiperfosfatemia. Todo esto implica una potencial disminución en la calidad de vida y aumento en la mortalidad.

Existen los siguientes biomarcadores de enfermedad ósea metabólica en pacientes con enfermedad renal crónica:

Tradicionales

- Fósforo

- Calcio

- Fosfatasa Alcalina

- iPTH

- 1,25 Vit D

\section{Nuevos biomarcadores \\ - FGF-23 \\ - Klotho \\ - Osteopontina \\ - Osteoprotegerina}

El FGF-23 producido en los osteocitos aumenta la excreción de fósforo a nivel renal. Se secreta en respuesta al aumento de vitamina D, P sérico y PTH. Reduce la vitamina D activa mediante inhibición de la actividad de la alfa-1-hidroxilasa en 
riñón. Señaliza a través de FGFR-1 y receptor Klotho que se encuentra casi exclusivamente en la glándula paratiroidea y riñón

Actúa directamente sobre hueso y riñón, y posiblemente en corazón.

Cabe destacar que los pacientes con nefropatía cursan con acidosis metabólica, anemia y en muchos casos dietas con res- tricción de proteínas. La poca actividad física es producto del malestar general que en ocasiones presentan por las comorbilidades (hipertensión arterial, insuficiencia cardíaca, etc.), lo cual, en ocasiones condiciona sarcopenia que, en conjunto con la mala calidad ósea, aumenta el riesgo de fracturas por fragilidad. El tratamiento en estos casos, es todo un reto para el clínico.

\section{Conferencia}

Rebote adiposo temprano y riesgo cardiometabólico futuro:

\section{edad de inicio vs. persistencia de la obesidad}

Raquel Burrows

EEndocrinóloga Infantil. Profesor Asociado, INTA. Universidad de Chile,

Chile.

\section{Un marco teórico desde la perspectiva evolutiva}

$\mathrm{Cu}^{\mathrm{l}}$ l creciente aumento de la obesidad, que afectó en un principio a países con mayor nivel de desarrollo socioeconómico, se relacionó con un 'genotipo ahorrador', que se programó hace 300 mil años. Esta programación permitió la sobrevida y reproducción del humano cazador-recolector en un entorno ancestral (Neels, 1962). Posteriormente, cuando la prevalencia de obesidad empieza a aumentar en países con menor nivel de desarrollo, donde la desnutrición había sido prevalente por décadas e incluso siglos, surge la hipótesis del 'fenotipo ahorrador' (Barker 1992). Según ésta, el ambiente nutricional prenatal y posnatal temprano desempeñan un papel fundamental en el desarrollo de la obesidad y las enfermedades crónicas no trasmisibles (ECNT) asociadas. Este periodo es crítico para el desarrollo del cerebro y de los tejidos adiposo y muscular, así como para la programación metabólica y neuroendocrina, adaptando al organismo al ambiente nutricional donde le tocará vivir, a través de una programación que incluye metilación del ADN y cambios en la disposición de histonas en genes relacionados con estas estructuras y funciones. Esta programación también puede afectar los mecanismos neurales que configuran respuestas conductuales relativas a la recompensa. Por ejemplo, se relaciona con una mayor sensibilidad de la vía mesolímbica y a una mayor predisposición a la conducta del comer gratificante con una mayor preferencia por todo lo que constituya una fuente potencial de placer. No debe extrañar, por tanto, que la discordancia entre esta programación epigenética y el ambiente al que se expone posteriormente un sujeto sea una fuente de disregulación metabólica y conductual y de enfermedades. Modelos animales y humanos coinciden en que esta programación se trasmite entre generaciones.

Evidencia más reciente (Weaver 2004) muestra que la exposición crónica al estrés, una condición muy prevalente en los grupos socialmente más vulnerables, también contribuye a una programación neonatal de funciones metabólicas $\mathrm{y}$ endocrinas que subyacen el comportamiento emocional y endocrino posterior. Esta programación neuroendocrina está asociada a una disregulación del eje hipotálamo-hipófisisadrenal (HHA), que se atribuye a una falla en la expresión del receptor hipotalámico de glucocorticoides. La disregulación del eje HHA se traduce en un mayor riesgo cardiovascular y metabólico debido a una secreción persistentemente aumentada de cortisol y mineralocorticoides, afectándose no sólo la homeostasis metabólica sino también la conducta. Así pues, el déficit nutricional al que estuvieron expuestas durante siglos la mayor parte de las poblaciones de América Latina favoreció una programación fenotípica ahorrativa relacionada con una programación metabólica y neuroendocrina que se trasmitió a las generaciones posteriores. Lo anterior, sumado a una transición nutricional acelerada hacia un ambiente dominado por la dieta occidental y el sedentarismo, ha favorecido la expresión de un sobrepeso mantenido en el tiempo y trastornos cardiometabólicos y conductuales que llevan tempranamente a la diabetes mellitus tipo 2, hipertensión arterial y a enfermedades cardiovasculares isquémicas, y elevan el riesgo de conductas adictivas.

Varios estudios de cohorte coinciden en que la obesidad temprana se asocia a obesidad en la vida adulta, confirmando una persistencia del canal de crecimiento en el tiempo. Asimismo, el rebote adiposo temprano se asocia a un mayor riesgo de insulino resistencia (IR) y desórdenes cardiometabólicos tanto en la adolescencia como en la adultez, confirmando como la exposición a un ambiente de abundancia contribuye a la expresión de un fenotipo de riesgo cardiovascular asociado a la 
obesidad temprana. Sin embargo, hay una creciente evidencia que muestra que esta programación epigenética "ahorradora" podría revertirse al cambiar el ambiente tempranamente.

\section{Nuestra experiencia en una cohorte de infancia}

Antecedentes: El Estudio Longitudinal de Santiago es una cohorte de infancia que reúne a $\sim 700$ jóvenes chilenos, socialmente vulnerables, que han sido evaluados desde los 4 meses de edad. En este grupo estudiamos la influencia del momento de inicio y de la persistencia de la obesidad en el perfil cardiometabólico de la adolescencia y la adultez emergente. Método: El IMC fue evaluado a los 5, 10, 16 y 22 años y el perfil cardiometabólico a los 16 y 22 años. Se formaron cuatro grupos de acuerdo con el momento de inicio y persistencia de la obesidad: Grupo 1 (nunca fueron obesos); Grupo 2 (obesos a los 5 años pero no en las evaluaciones posteriores); Grupo 3 (obesos a los 16 y/o 22 años); Grupo 4 (obesos a los 5, 10, 16 y 22 años). Resultados: Hallamos mayor prevalencia de obesidad a los 10, 16 y 22 años (73\%, 50\% y 57\%, respectivamente) en los participantes que rebotaron tempranamente (Grupos 2 y 4) comparado con aquellos que no rebotaron $(18 \%, 6 \%$ y $15 \%$ respectivamente) (Grupos 1 y 3 ). Sin embargo, al evaluar el perfil cardiometabólico de los 16 y 22 años considerando el momento de inicio y la persistencia de la obesidad, observamos que sólo los sujetos de los Grupos 3 y 4, es decir con obesidad tardía o persistente, tuvieron un perfil cardiometabólico alterado comparado con los participantes que nunca fueron obesos (Grupo 1). Los participantes que rebotaron tempranamente pero luego superaron la obesidad (Grupo2), si bien tuvieron un mayor IMC y perímetro de cintura que los participantes del Grupo 1, mostraron un perfil cardiometabólico en la adolescencia y adultez emergente que no se diferenció del perfil del Grupo 1. Conclusión: Estos resultados muestran que no sería el rebote adiposo temprano sino la persistencia de la obesidad de quienes rebotan tempranamente, lo que determina un mayor riesgo cardiometabólico. Estos hallazgos confirman la necesidad de políticas públicas dirigidas tanto a la prevención como a la intervención temprana de la obesidad. Existiría en las poblaciones más vulnerables una programación metabólica y neuroendocrina favorecedora del sobrepeso y del riesgo cardiometabólico, que sería heredable, y que afectaría tanto la homeostasis metabólica como la toma de decisiones generadoras de bienestar. La implementación de políticas públicas y programas de salud adecuadamente fundamentados en la evidencia científica podría revertir el daño asociado a la obesidad temprana.

\title{
Conferencia
}

\section{Hasta dónde debemos tener en cuenta} consideraciones de economía de la salud en nuestra práctica clínica

\author{
Juan José Gagliardino
}

CENEXA. Centro de Endocrinología Experimental y Aplicada (UNLPCONICET). Facultad de Ciencias Médicas, UNLP, La Plata, Argentina.

$\mathrm{L}$ a atención de personas con diabetes mellitus tipo 2 (DM2) y otros factores de riesgo cardiovascular (FRCV)

asociados consume una cantidad creciente de recursos. Estos recursos -siempre escasos frente a la demanda- son provistos por la salud pública, la seguridad social y las empresas de cobertura de salud. En consecuencia representan un condicionante, ciertamente no el único pero sí una barrera importante a franquear para poder proveer la calidad de atención necesaria que asegure un buen control clínico y metabólico de las pacientes mencionados. Solo de esa manera podremos prevenir el desarrollo y progresión de las complicaciones crónicas de la enfermedad que aumentan los costos de su atención y disminuyen su calidad de vida. En consecuencia y dado que la discusión del tema se desarrollará en el ámbito de la economía de la salud, será importante poner más énfasis en los costos sin por ello ignorar argumentos basados en aspectos moleculares de la enfermedad. Esto no implica desconocer la importancia de estos últimos sino ubicar la discusión en el contexto más apropiado.

En este sentido valdría la pena analizar el impacto del diagnóstico tardío, la presencia de obesidad, del grado de control metabólico logrado y la presencia de complicaciones crónicas de la enfermedad sobre los costos directos de la DM2 y los FRCV asociados. Igualmente, incluir en dicho análisis las posibles alternativas de solución del problema planteado basadas en evidencias locales, regionales e internacionales.

La evidencia disponible muestra que el impacto del retraso del diagnóstico de DM2 aumenta más el riesgo de desarrollar eventos cardiovasculares de alto costo, es significativamente mayor que la diferencia entre administrar tratamiento intensivo versus convencional. Sin embargo y lamentablemente, este retraso es frecuente en nuestro medio especialmente en el nivel primario de atención. 
En nuestra región, la evidencia muestra que en personas con DM2 con un grado de control glucometabólico (glucemia de ayunas y HbA1c) comparable, el costo total del tratamiento farmacológico de la hiperglucemia y los FRCV asociados aumenta significativamente $(p<0,001)$ y en forma independiente, en función del incremento del índice de masa corporal (IMC)). A pesar de ello, la obesidad se asocia al $80 \%$ de las personas con DM2 y su control efectivo continúa siendo una de las asignaturas pendientes en el tratamiento de estos pacientes.

Resultados recientes obtenidos mediante el análisis de datos de gran cantidad de personas con DM2 de nuestra región demuestran que aquellos que alcanzan las metas terapéuticas de HbA1c consumen anualmente una cantidad significativamente menor de recursos que aquellos que no alcanzan dichas metas. Lamentablemente, menos del $50 \%$ de las personas con DM2 alcanzan dichas metas y menos aún si consideramos el alcance de metas combinadas (IMC, HbA1c, presión arterial y perfil lipídico).

Cuando comparamos los costos directos de atención (desde la consulta hasta las posibles internaciones hospitalarias) de personas sin y con DM2 apareadas por edad y género, ellos son un $78 \%$ mayores el segundo grupo. La diferencia se cuadriplica cuando comparamos los costos directos de personas sin diabetes con los de personas con DM2 que han desarrollado complicaciones crónicas de la enfermedad.
Si nos limitáramos solo a la descripción de la problemática económica de la DM2 no solo no aportaríamos soluciones sino que tan solo seríamos parte de la misma. En consecuencia pretendemos describir una estrategia cuya implementación en diversos ámbitos socioeconómicos y culturales ha sido capaz de disminuir la pesada carga económica de la DM2. En este sentido la implementación de un programa estructurado de educación de personas con DM2 en 10 países de nuestra región, produjo en los 12 meses posteriores al mismo, una disminución significativa del consumo y costo de medicamentos para el control de la hiperglucemia y los FRCV asociados.

La implementación de programas educativos mostró también una optimización del uso de medicamentos cuando la educación incluyó simultáneamente a médicos y pacientes. Posteriormente, la implementación de un programa educativo de integrantes del equipo de salud (médicos y enfermeras) del nivel primario de atención en un área crítica de Argentina, asociada a ajustes en el área de gestión y registro sistemático de variables clínicas, metabólicas y terapéuticas mejoró significativamente todos los indicadores clínicos y metabólicos de calidad de atención evaluados.

En función de lo expuesto creemos que la enorme carga socioeconómica impuesta por la DM2 puede disminuirse efectivamente implementando estrategias educativas capaces de mejorar actitudes diagnósticas, prevención primaria y secundaria al igual que estilos prescriptivos inadecuados.

\section{Conferencia}

\section{¿Estamos listos para implementar programas de prevención primaria en Latinoamérica?}

\section{Pablo Aschner}

Universidad Javeriana, Hospital Universitario San Ignacio y Asociación Colombiana de Diabetes, Bogotá, Colombia.

0 e han publicado al menos 6 estudios clínicos controlados y aleatorizados que demuestran la efectividad de intervenir personas con alto riesgo de desarrollar diabetes mellitus tipo 2 (DM2) con cambios intensivos en el estilo de vida (CIEV) con el objetivo de prevenir esta enfermedad (prevención primaria). La gran mayoría han seleccionado personas con intolerancia a la glucosa (ITG) identificados por diferentes estrategias de tamización. En ellos los CIEV pueden reducir el riesgo de desarrollar diabetes hasta en más de un $50 \%$ al cabo de unos tres años y el principal factor parece ser la pérdida de peso (al menos $5 \mathrm{~kg}$ ). También se han comparado diferentes fármacos antidiabéticos y antiobesidad con placebo, pero al parecer los CIEV son más efectivos a largo plazo. Se requiere aproximadamente un número necesario a tratar (NNT) de 25 para prevenir un caso de diabetes.

Con esta evidencia se puede hacer una recomendación fuerte para iniciar un programa de CIEV en personas con ITG e inclusive se podría extrapolar como una recomendación débil a personas con alto riesgo de desarrollar diabetes determinado por una escala predictora de dicho riesgo. Existen al menos dos programas a escala nacional para implementar CIEV en esta población, aplicando las estrategias que se utilizaron en los estudios clínicos controlados. Aunque todavía no han demostrado una reducción en la incidencia de DM2, sí han logrado modificar algunos factores de riesgo y en particular el peso.

La implementación de un programa de prevención primaria de diabetes a una región con diferentes etnias, estilos de vida y cultura como Latinoamérica (LA) requiere un complejo proceso de transculturización. En el tema que nos ocupa, esto implica la incorporación de factores culturales para optimizarla. Esto genera varios retos, comenzando por la validación del proceso de tamización para identificar individuos en alto riesgo. Aunque la glucemia en ayunas sigue siendo una prueba con alta sensibilidad y la prueba de tolerancia a la glucosa tiene la mayor especificidad para el diagnóstico de ITG y DM2 (al fin y al cabo es la prueba de oro), estas son aplicables principalmente a las personas que acuden a los servicios de salud y que 
son tamizados "oportunísticamente". Las escalas de riesgo que no incluyen pruebas de laboratorio permiten extender la tamización a la población general y la más usada es el FINDRISC desarrollado en Finlandia. Esta escala ya ha sido adaptada para LA (LA-FINDRISC) mediante la introducción de los puntos de corte de la circunferencia de cintura que permiten identificar individuos con obesidad abdominal en nuestra población y ha demostrado ser costo-efectiva para seleccionar personas que ameritan un examen de laboratorio para detectar diabetes. Su punto de corte debe ser validado localmente y depende del uso que se desea dar a la escala.

Pero el reto más grande es la implementación del programa de CIEV en las personas identificadas con alto riesgo (principalmente con ITG). Se han hecho varios estudios clínicos controlados en LA con muestras pequeñas que han demostrado cambios significativos en los parámetros metabólicos. Uno de ellos se llevó a cabo en Barranquilla (DEMOJUAN) aplicando un programa semiestructurado basado en el estu- dio Finlandés. Al cabo de dos años casi la mitad revirtieron a una tolerancia a la glucosa normal, inclusive en el grupo control, sugiriendo que el programa permeó a toda la población en riesgo. Actualmente estamos llevando a cabo un programa más extenso en Barranquilla y Bogotá (PREDICOL) que pretende aplicar un programa estructurado basado en el NDPP dirigido a las personas con alto riesgo (particularmente con ITG), pero que también incluye una intervención comunitaria para evaluar los cambios cardiometabólicos en todos los niveles de riesgo.

Hasta el momento, es evidente que la prevención primaria es viable en LA y debe incluirse en las guías de manejo de DM2 para aquellos que durante el proceso diagnóstico resultan con prediabetes, pero todavía falta evidencia que permita recomendar una tamización poblacional con el propósito de introducir CIEV. La población debe estar motivada para el cambio y los servicios de salud deben estar preparados para implementar el programa.

\title{
Conferencia
}

\section{Ginecomastia}

\author{
Pablo Knoblovits (Argentina)
}

La ginecomastia es la presencia de tejido mamario palpable en el varón; es una alteración frecuente, ya que se presenta fisiológicamente en tres periodos de la vida: en más del 50\% de los recién nacidos, en aproximadamente el $40 \%$ de los púberes y en hasta el $50 \%$ de los hombres mayores. Es una causa frecuente de consulta y, aunque generalmente es benigna, produce ansiedad e incomodidad. La prevalencia depende del criterio que se utilice para su definición.

Se puede presentar como un pequeño botón retroareolar o llegar a ser una colección fibroadiposa de mayor tamaño, que

semeja la mama femenina y resulta difícil de diferenciar de la lipomastia (hiperplasia del tejido adiposo sin proliferación del parénquima mamario). Puede ser unilateral o bilateral, simétrica o asimétrica; la variedad simétrica bilateral es la forma de presentación más frecuente en todas las edades. Es importante diferenciar la presencia de tejido mamario palpable asintomático, que tiene poca relevancia clínica, de un agrandamiento mamario de comienzo reciente, generalmente asociado a dolor y tumefacción, que puede ser signo de enfermedad.

\section{Principales mecanismos fisiopatológicos de la ginecomastia}

\begin{tabular}{|l|l|}
\hline \multicolumn{1}{c|}{ Alteración } & \multicolumn{1}{c}{ Fisiopatología } \\
\hline $\begin{array}{l}\text { Hipogonadismo hipergonadotrófico congénito o } \\
\text { adquirido (falla testicular) }\end{array}$ & $\begin{array}{l}\text { - Disminución de la producción de testosterona. } \\
\text { - Aumento de la producción de estradiol testicular por estimulación de la } \\
\text { aromatasa producida por acción de la LH (sobres la célula de Leydig) y de } \\
\text { la FSH (sobre la célula de Sertoli). }\end{array}$ \\
\hline $\begin{array}{l}\text { Hipogonadismo hipogonadotrófico congénito o } \\
\text { adquirido (falla hipotálamo-hipofisaria) }\end{array}$ & - Disminución de la producción de testosterona. \\
\hline $\begin{array}{l}\text { Hipertiroidismo } \\
\text { Tumores de células germinales (testiculares o } \\
\text { extratesticulares) }\end{array}$ & $\begin{array}{l}\text { - Aumento de GLAE con disminución de la testosterona biodisponible } \\
\text { - Aumento de la aromatización. }\end{array}$ \\
\hline $\begin{array}{l}\text { Tumores no germinales productores de } \text { hCG } \\
\text { (producción ectópica) }\end{array}$ & $\begin{array}{l}\text { - Aumento de la aromatización. } \\
\text { célula de Leydión de hCG con estimulación de la producción de estradiol por la }\end{array}$ \\
\hline
\end{tabular}




\begin{tabular}{l|l}
\hline Tumores de células de Leydig o Sertoli & $\begin{array}{l}\text { Aumento de la producción de estradiol con inhibición de las gonadotro- } \\
\text { pinas, que produce disminución de la producción de testosterona. }\end{array}$ \\
\hline Tumores adrenales feminizantes & $\begin{array}{l}\text { Aumento de la producción de estradiol con inhibición de las gonadotro- } \\
\text { pinas, que provoca disminución de la producción de testosterona. }\end{array}$ \\
\hline Renutrición & $\begin{array}{l}\text { Regresión del eje gonadal a estadios prepuberales durante la desnutri- } \\
\text { ción por lo que provoca un estado de "nueva pubertad" durante la renu- } \\
\text { trición. }\end{array}$ \\
\hline Cirrosis & $-\begin{array}{l}\text { Disminución de la depuración de androstenediona, lo que aumenta el } \\
\text { sustrato para la aromatización. }\end{array}$ \\
\hline Insuficiencia renal & - Aumento de GLAE con disminución de la testosterona biodisponible. \\
\hline Infección por VIH & $\begin{array}{l}\text { Falla testicular y disminución de la producción de } \\
\text { testosterona y aumento de FSH y LH. }\end{array}$ \\
\hline & $-\quad$ Hipogonadismo \\
- & Efecto adverso del tratamiento antirretroviral. \\
\hline & - Otros fármacos utilizados en el tratamiento \\
\hline
\end{tabular}

Fármacos que pueden causar ginecomastia

\begin{tabular}{|c|c|c|}
\hline Mecanismo de acción & \multicolumn{2}{|c|}{ Fármaco } \\
\hline Hormonas & \multicolumn{2}{|c|}{$\begin{array}{l}\text { Andrógenos y esteroides anabólicos* } \\
\text { hCG* } \\
\text { Estrógenos y agonistas estrogénicos* }\end{array}$} \\
\hline $\begin{array}{l}\text { Antiandrógenos o inhibidores de la síntesis de } \\
\text { andrógenos }\end{array}$ & \multicolumn{2}{|l|}{$\begin{array}{l}\text { Ciproterona* } \\
\text { Flutamida* } \\
\text { Finasteride* }\end{array}$} \\
\hline Antibióticos & \multicolumn{2}{|l|}{$\begin{array}{l}\text { Isoniazida } \\
\text { Ketoconazol* } \\
\text { Metronidazol. }\end{array}$} \\
\hline $\begin{array}{l}\text { Medicamentos inhibidores de la secreción } \\
\text { gástrica }\end{array}$ & \multicolumn{2}{|l|}{$\begin{array}{l}\text { Cimetidina* } \\
\text { Ranitidina } \\
\text { Omeprazol }\end{array}$} \\
\hline Medicamentos quimioterápicos & \multicolumn{2}{|c|}{ Principalmente agentes alquilantes } \\
\hline $\begin{array}{l}\text { Fármacos con efecto sobre el sistema cardio- } \\
\text { vascular }\end{array}$ & $\begin{array}{l}\text { Amiodarona } \\
\text { Captopril } \\
\text { Digoxina* } \\
\text { Enalapril } \\
\text { Metildopa }\end{array}$ & $\begin{array}{l}\text { Nifedipina } \\
\text { Reserpina } \\
\text { Espironolactona* } \\
\text { Verapamilo } \\
\text { Diltiazem }\end{array}$ \\
\hline Fármacos psicotrópicos & $\begin{array}{l}\text { Diazepam } \\
\text { Haloperidol }\end{array}$ & $\begin{array}{l}\text { Fenotiazinas } \\
\text { Antidepresivos tricíclicos }\end{array}$ \\
\hline Drogas de abuso & $\begin{array}{l}\text { Alcohol } \\
\text { Anfetaminas }\end{array}$ & $\begin{array}{l}\text { Heroína } \\
\text { Marihuana }\end{array}$ \\
\hline Antirretrovirales & \multicolumn{2}{|c|}{$\begin{array}{l}\text { Inhibidores de la transcriptasa reversa } \\
\text { Inhibidores de la proteasa }\end{array}$} \\
\hline Otras & $\begin{array}{l}\text { Difenilhidandoína } \\
\text { Dong quai }\end{array}$ & $\begin{array}{l}\text { Rofecoxib } \\
\text { Talidomida }\end{array}$ \\
\hline
\end{tabular}

*Fármacos con fuerte asociación con ginecomastia 


\section{Tratamiento farmacológico}

\section{Andrógenos}

Testosterona: La respuesta al tratamiento en pacientes con ginecomastia asociada a hipogonadismo es muy buena. En los pacientes con funcionamiento gonadal normal no se ha demostrado que sea más eficaz que no realizar tratamiento. Existe el riesgo de agravar la ginecomastia por aumento de la aromatización a estradiol. Se demostró su efectividad en pacientes con cirrosis.

Dihidrotestosterona: Es un andrógeno no aromatizable, no disponible en Argentina.

\section{Antiestrógenos}

Es el tratamiento más utilizado en pacientes con ginecomastia dolorosa de etiología desconocida y de comienzo reciente. Es difícil conseguir la remisión completa con cualquiera de estos fármacos.

- Clomifeno: se utilizan dosis de 50 a 100 mg por día, durante periodos de 3 a 6 meses. El tratamiento puede suspenderse si no se observa respuesta a la octava semana de su inicio. Se ha comunicado que la dosis de $100 \mathrm{mg}$ administrada durante seis meses es la más efectiva (64\%). Es un fármaco seguro.
- Tamoxifeno: se ha demostrado su efectividad en estudios aleatorizados (pero con un número bajo de pacientes), en dosis de 10 a $40 \mathrm{mg}$ diarios durante tres meses.

- Raloxifeno (modulador del receptor de estrógenos): se ha reportado efectividad, aunque la experiencia es aún insuficiente.

\section{Inhibidores de la aromatasa}

Se ha comunicado el tratamiento con testolactona o anastrazol, pero su efectividad no está establecida. Pueden tener un rol más importante en pacientes seleccionados con aumento de la aromatización de andrógenos a estrógenos (síndrome de exceso familiar de aromatasa, tumores testiculares con aumento de actividad de aromatasa, pacientes con aumento de hCG).

\section{Tratamiento quirúrgico}

La ginecomastia es una preocupación estética para el paciente. Se recomienda el tratamiento quirúrgico cuando el tratamiento médico no ha sido exitoso o en los casos de ginecomastia de larga evolución (más de 12 a 18 meses).

\title{
Conferencia
}

\section{La disfunción eréctil en el síndrome metabólico}

\author{
Pablo Knoblovits
}

\section{Introducción}

$\mathrm{L}$ os profundos cambios de estilo de vida, alimentación, sedentarismo, adquisición de hábitos nocivos como tabaquismo y alcoholismo, proceso de urbanización y envejecimiento de la población que ocurrieron en los últimos años determinan la aparición de nuevas enfermedades. Una de ellas es el síndrome metabólico (SM), que se define como una entidad clínica constituida por un conjunto de factores (hipertensión arterial, obesidad abdominal, hiperglucemia, dislipemia) que interactúan y determinan un riesgo elevado de padecer enfermedad cardiovascular (ECV) y diabetes mellitus tipo 2 (DM2). Por lo tanto, es de suma importancia la detección e intervención temprana en dichos pacientes para prevenir su evolución a las patologías mencionadas.

Las bases fisiopatológicas de este síndrome son la obesidad abdominal a predominio visceral y la insulino-resistencia (IR).

Diferentes organismos y asociaciones médicas intentaron elaborar una definición de SM, pero no hay consenso en adoptar una definición única y universal que sirva como herramienta de aplicación clínica. Las dos definiciones más utilizadas en la práctica clínica son las de la IDF y NCEP-ATP III. La detección de SM y su tratamiento es fundamental para la prevención de ECV y DM2, pero también tiene un fuerte impacto desde el punto de vista andrológico en la función eréctil, función gonadal endocrina y también reproductiva.

No hay datos epidemiológicos de todos los países latinoamericanos sobre prevalencia de SM y los diferentes estudios difieren en la definición que se utilizó para el diagnóstico de SM, el grupo etario, la proporción de hombres y mujeres incluidos y el ámbito poblacional (urbano, rural, aborigen). En términos generales, en Latinoamérica, una de cada 3 o 4 personas mayores de 20 años cumple criterios para el diagnóstico de SM.

\section{Síndrome metabólico y disfunción eréctil}

En condiciones fisiológicas, la insulina tiene una acción hemodinámica: luego de atravesar la barrera endotelial, la insulina promueve la relajación del esfínter precapilar lo que determina la vasodilatación capilar; como consecuencia de esto se reclutan una mayor cantidad de microvasos, se expande la red capilar y la perfusión microvascular periférica aumenta. La acción vasodilatadora de la insulina se ejerce a través de la síntesis de $\mathrm{ON}$ en las células endoteliales, dado que la insulina estimula en forma directa la expresión y la activación de la ON sintetasa. 
La IR presente en la mayoría de los sujetos que presentan obesidad, SM y DM2, es una alteración metabólica que produce disfunción endotelial determinada por menor síntesis y liberación de $\mathrm{ON}$, combinado con un consumo exagerado del mismo en tejidos expuestos a altas concentraciones de radicales libres. La disminución en los niveles de ON afecta las diferentes arterias del organismo comprometiendo el mecanismo de vasodilatación. Es probable que esta disfunción endotelial causada por la IR esté presente también en los cuerpos cavernosos de pacientes con disfunción eréctil (DE), comprometiendo en este caso los mecanismos eréctiles. El pequeño diámetro (1-2 $\mathrm{mm}$ ) y el relativamente alto contenido de células endoteliales y musculares lisas por unidad de volumen de tejido comparado con otros órganos, determina que las arterias cavernosas sean más susceptibles al daño por estrés oxidativo.

Los estudios que evaluaron la presencia de IR en hombres con DE estiman una prevalencia de $77-79 \%$ de IR en estos sujetos. En un estudio evaluamos la prevalencia de IR utilizando el índice HOMA (Homeostasis Model Assessment) en pacientes con DE y observamos una prevalencia de IR de $77,5 \%$ en sujetos con DE vs. $45 \%$ en sujetos sin DE. Se observó también peor función eréctil en pacientes con diagnóstico de IR y una correlación negativa entre el puntaje de función eréctil y el índice HOMA ${ }^{1}$.

La DE afecta a un porcentaje importante de la población masculina, con una prevalencia de 30\%-70\% entre los 40 y 70 años de edad. Entre los factores que se asocian a DE se incluyen: depresión, alteraciones hormonales y alteraciones vasculares o neurológicas secundarias a trauma o cirugía. También se asocia la DE a diferentes alteraciones endocrino-metabólicas que determinan mayor riesgo de ECV como DM2 y componentes del SM: hipertensión arterial, obesidad y dislipemia. Además la presencia de DE puede ser un marcador temprano de ECV, en estudios prospectivos se observó que la presencia de DE se asocia a un incremento de 1.6 veces de riesgo de ECV.

En un estudio realizado por nuestro grupo de trabajo que incluyó 81 pacientes con DE, se halló una prevalencia de SM de $68,5 \%$ según criterios IDF y 52,1\% según criterios ATPIII, en ambos casos la prevalencia fue significativamente mayor que en pacientes del grupo control sin DE. Un dato para remarcar de este estudio es que a partir de la consulta por DE y la evaluación de los diferentes componentes del SM se detectaron 20 casos nuevos de hipertensión arterial y 24 casos nuevos de dislipemia, por lo que consideramos de suma importancia evaluar los componentes del SM en pacientes con DE para prevenir la eventual progresión a ECV o DM2 futura.

Teniendo en cuenta que los pacientes con DE tienen mayor prevalencia de IR y que esta alteración podría ser uno de los mecanismos fisiopatológicos que producen la DE, el tratamiento farmacológico de la misma podría mejorar la función eréctil. Con esta hipótesis hemos llevado a cabo un estudio prospectivo, aleatorizado, doble ciego con placebo en 30 pacientes con DE e IR con poca respuesta a sildenafil a dosis máxima. Un grupo de pacientes recibió metformina $1.700 \mathrm{mg} /$ día y sildenafil a demanda durante cuatro meses y el otro grupo placebo de metformina y sildenafil a demanda durante cuatro meses. En el grupo de pacientes que recibió metformina se observó disminución del IMC y del índice HOMA y un aumento significativo del puntaje de función eréctil ${ }^{3}$.

Los mecanismos fisiopatológicos explicados y los hallazgos descritos permiten pensar la disfunción eréctil como manifestación y consecuencia de un trastorno endotelial.

Otro de los mecanismos que pueden estar involucrados en la aparición de DE en pacientes con SM es la menor síntesis de testosterona. El hipogonadismo determina menor síntesis de ON, disminución de libido y menor respuesta al tratamiento con inhibidores de la fosfodiesterasa 5.

\section{Conferencia}

\section{Hiperaldosteronismo primario}

\section{Alejandro Román González ${ }^{1}$, Carlos Alfonso Builes-Barrera ${ }^{1}$.}

\footnotetext{
${ }^{1}$ Internista Endocrinólogo Hospital Universitario San Vicente Fundación. Profesor Sección Endocrinología y Diabetes, Departamento de Medicina Interna, Universidad de Antioquia, Medellín, Colombia.
}

\section{Introducción}

El hiperaldosteronismo primario es la principal causa de hipertensión de origen endocrino. Su prevalencia incrementa con la gravedad de la hipertensión. Sin embargo, existe un subdiagnóstico, influido por la complejidad del diagnóstico que requiere mediciones hormonales bajo condiciones estrictas de preparación, uso de pruebas confirmatorias no disponibles de manera frecuente y la necesidad de estudios complejos y costosos como el cateterismo selectivo de venas suprarrena- les. Adicionalmente, las guías internacionales de hiperaldosteronismo indican su estudio en poblaciones selectas con mayor probabilidad pre-prueba de hiperaldosteronismo, desconociendo la presencia de esta enfermedad en estadios iniciales de la HTA e incluso en estadios subclínicos. Por ende, se requiere simplificar el diagnóstico de esta enfermedad y ampliar la base poblacional que se estudia para hiperaldosteronismo.

\section{Hiperaldosteronismo clásico}

Esta enfermedad fue descrita por el doctor Jerome Conn hace casi 60 años cuando presentó su conferencia en la Sociedad Central para la Investigación Clínica en Chicago, Estados Unidos. El fenotipo inicial de la enfermedad era caracteriza- 
do por la presencia de HTA grave, de difícil manejo, asociado a hipocaliemia y alcalosis metabólica. La prevalencia clásica en hipertensos varía entre el 5\% y el $20 \%$. Es más frecuente en poblaciones con fenotipos más graves o más resistentes de hipertensión. Sin embargo, en países desarrollados se ha demostrado que solo se estudian menos del $10 \%$ de los pacientes con hipertensión para hiperaldosteronismo. Incluso, estudios recientes estiman en menos de un $2 \%$ los casos diagnosticados del total esperado poblacionalmente. Definitivamente, se requiere una búsqueda mayor de casos de hiperaldosteronismo tal como lo indica la guía, e incluso expandir la búsqueda a casos no tan sugestivos de hiperaldosteronismo, ejemplo: hipertensión estadio I. Las indicaciones actuales de la guía son: presión arterial mayor de 150/100, hipertensión resistente, hipertensión e hipocaliemia (espontánea o inducida por diurético), incidentaloma adrenal con hipertensión, hipertensión con historia familiar de enfermedad cerebrovascular o hipertensión de inicio temprano, hipertensión arterial y apnea obstructiva del sueño y los familiares hipertensos de pacientes con hiperaldosteronismo.

\section{Hiperaldosteronismo subclínico}

Desde hace varios años tenemos estudios que sugieren que el porcentaje de pacientes con hiperaldosteronismo es mayor al reportado. Inicialmente se medía aldosterona urinaria encontrando exceso de esta hormona en el 50\% de los pacientes. Reciente, el grupo de investigación del Dr. Vaidya y el grupo chileno en cabeza del Dr. Braudand reportaron hallazgos muy interesantes en dos estudios. El primero en pacientes con elevación de aldosterona urinaria, pero con relación aldo/ renina normal y el segundo en pacientes con prehipertensión donde sugieren que estos pacientes tienen tasas de complicaciones más elevadas desde el punto de vista cardiovascular. Por ende, nos debemos cuestionar si estamos llegando muy tarde al diagnóstico de hiperaldosteronismo. Este parámetro es de vital importancia dado que en el PASO se encontró que pacientes con cura completa de la hipertensión con el manejo quirúrgico tenían una duración de la enfermedad más corta comparado con pacientes no curados.

\section{Complicaciones del hiperaldosteronismo}

Las complicaciones clásicas del hiperaldosteronismo son hipocaliemia con rabdomiólisis, hipertensión y alcalosis metabólica. Adicionalmente, los pacientes con hiperaldosteronismo primario tienen mayores tasas de desenlaces cardiovasculares a pesar de tener el mismo valor de presión arterial. Esto refleja los efectos deletéreos mediados por múltiples mecanismos, por ejemplo, la fibrosis de la aldosterona en el sistema cardiovascular.

Otras complicaciones del hiperaldosteronismo primario son:

- Apnea del sueño: los pacientes con apnea del sueño tienen concentraciones mayores de aldosterona y esta se correlaciona con el índice de apneas e hipopneas. Existe una relación circular en esta enfermedad dado que la aldosterona parece jugar un papel en la fisiopatología, pero la misma apnea activa el sistema renina angiotensina aldosterona.

- Diabetes: Los pacientes con hiperaldosteronismo primario tiene mayores tasas de síndrome metabólico, glucosa y mayor riesgo de diabetes tipo 2 comparado con hipertensión esencial. Estudios han encontrado que la hipertensión en el hiperaldosteronismo precede la diabetes y la aldosterona per se parece favorecer la resistencia a la insulina.

- Fibrilación auricular (FA): los pacientes con hiperaldosteronismo primario tienen un incremento en el riesgo de FA 7-12 veces mayor que los pacientes hipertensos esenciales. La aldosterona promueve la hipertrofia cardíaca, fibrosis, inflamación, disfunción diastólica y dilatación de la aurícula izquierda. Esto favorece el desarrollo de la FA. Se requieren estudios adicionales.

- Deterioro óseo: Estudios recientes sugieren que el hiperaldosteronismo tiene un efecto deletéreo en el hueso. Se ha asociado con mayor hipercalciuria, mayores tasas de hiperaldosteronismo en pacientes osteoporóticos comparados con los sanos y mayores tasas de fracturas, en particular fracturas vertebrales.

\section{Avances en la fisiopatología}

Modelo del grupo de células productoras de aldosterona (APCC, del inglés aldosterone producing cell cluster):

Una de las teorías actuales en el desarrollo del hiperaldosteronismo es la presencia de grupos celular productores de aldosterona. En este caso una mutación en un gen conduce a la formación de APCC lo que en el tiempo conduce al adenoma. Se ha encontrado mutaciones en CACNA1D., ATP1A y ATP2b3. Sin embargo, en estas APCC no se han encontrado mutaciones en KCNJ5, que es la mutación más frecuente en adenoma productor de aldosterona. Una segunda teoría es el requerimiento de un segundo golpe genético para desarrollar el hiperaldosteronismo. En este sentido, la APCC puede desarrollar en el tiempo mutaciones en KCNJ5 y desarrollar hiperaldosteronismo.

\section{Formas monogénicas}

Hiperaldosteronismo familiar tipo I: Conocido como hiperaldosteronismo remediable por glucocorticoides. Su causa es la formación de un gen quimérico entre los generes CYP11B11 que codifica para la 11b-hidroxilasa y el gen CYP11B2 que codifica para la aldosterona sintasa. Eso hace que la ACTH estimule la producción de aldosterona. Se trata con glucocorticoides.

Hiperaldosteronismo familiar tipo II: Se desconoce la mutación causante. El fenotipo es indistinguible de los pacientes con hiperaldosteronismo clásico. Se diagnostica en familiares con ausencia de mutaciones para hiperaldosteronimo familiar tipo I, III o IV

Hiperaldosteronismo familiar tipo III: Se produce por mutaciones en el gen KCNJ5. Produce una forma grave de hiperaldosteronismo con hiperplasia adrenal bilateral. 
Hiperaldosteronismo familiar tipo IV: Recientemente se describió en pacientes con mutaciones en gen CACNA1H que codifica para el canal de calcio tipo T.

Otras mutaciones: en pacientes con hiperaldosteronismo, convulsiones y anomalías neurológicas (PASNA, del inglés: primary aldosteronism with seizures and neurological abnormalities) se encontró mutaciones en gen CACNA1D. El hiperaldosteronismo con desorden del desarrollo se encontró mutaciones en CACNA1H.

\section{Diagnóstico y tratamiento. ¿Podemos hacer algo mejor?}

Se debe descartar hiperaldosteronismo en personas con fenotipos de hipertensión resistente o historia familiar o casos graves acompañados de hipocaliemia. En estos escenarios la prueba indicada es la medición de renina (actividad o masa) y aldosterona. El diagnóstico es certero cuando tenemos una renina suprimida (actividad $<0,3 \mathrm{ng} / \mathrm{ml} /$ hora) con una aldosterona elevada mayor de $20 \mathrm{ng} / \mathrm{dl}$ con hipocaliemia. Tanto que en este contexto no es necesario realizar pruebas confirmatorias y se puede proceder a imágenes de localización inmediatas. Ahora bien, una renina baja o suprimida nos indica un fenotipo de HTA con renina baja que en la mayoría de escenarios será una enfermedad endocrina la causa de base, bien sea un hiperaldosteronismo primario u otra enfermedad como el síndrome de Cushing, el exceso aparente de mineralocorticoides, el síndrome de Liddle, el síndrome de Gordon y algunas formas de hiperplasia adrenal congénita. Luego de confirmar una relación aldosterona/renina elevada se debe proceder a un estudio confirmatorio. En nuestro hospital hacemos rutinariamente la prueba de infusión de solución salina (2 litros en 4 horas vía venosa). Una aldosterona posinfusión elevada (mayor de $10 \mathrm{ng} / \mathrm{dl}$ ) indica hiperaldosteronismo primario y se debe proceder a una tomografía suprarrenal.

Es controversial si el manejo guiado por TAC comparado con el cateterismo es mejor o no. El estudio más grande a la fecha y mejor diseñado ha sido criticado ampliamente, pero sugiere que los desenlaces son similares si se hace una estrategia guiada por TAC o guiada por cateterismo, con un diferencial importante, el costo, además de que en muchos sitios no existe la disponibilidad del personal entrenado y los equipos necesarios.

Manejo médico: La terapia médica de excelencia es el uso de antagonistas de la aldosterona como espironolactona o eplerenona. Los objetivos con estos medicamentos son normalizar la presión arterial y el valor de potasio. Adicionalmente debe evaluarse la renina como marcador de control de la enfermedad. Los pacientes que a pesar de tratamiento médico tienen una renina suprimida tienen peores desenlaces que aquellos pacientes con renina normalizada. Una meta propuesta es la una actividad de renina mayor de $1 \mathrm{ng} / \mathrm{ml} /$ hora $(\geq 1 \mu \mathrm{g} / \mathrm{L} / \mathrm{h})$.

\section{Conferencia}

\section{Obesidad, efectos ambientales y compuestos químicos}

\section{Fernando Lizcano}

Profesor Titular

Director Centro de Investigación Biomédica,Universidad de la Sabana Endocrinólogo Asociado, Fundación Cardioinfantil, Bogotá, Colombia.

\section{$\mathrm{L}$} os químicos disruptores endocrinos (EDC) son sustancias que se localizan en el ambiente y pueden desencadenar una serie de eventos en la regulación de la actividad hormonal preferentemente en la función de hormonas sexuales y tiroideas.

Se ha observado que eventualmente estas sustancias químicas pueden ocasionar una alteración de la actividad metabólica del cuerpo generando una mayor actividad lipogénica.

Las células adiposas funcionalmente se pueden clasificar como de actividad endocrina y sensibles a los cambios inducidos por los disruptores endocrinos que se han denominado como "obesógenos". Estas sustancias pueden desencadenar aumento de la adiposidad mediante alteración del programa del desarrollo celular en el adipocito, aumentado el almacenamiento de triglicéridos e interfiriendo con el control neuroendocrino de los centros del hambre y la saciedad.

La prevalencia de obesidad viene aumentando ostensiblemente debido al sedentarismo y las costumbres dietéticas. No obstante, a pesar de implantar una serie de medidas públicas para contrarrestar estas circunstancias, la obesidad se observa entre el $20 \%$ al $35 \%$ de la población adulta en el mundo con un aumento persistente en la población infantil.

En vista de que en muchas circunstancias donde la dieta y la actividad física han logrado implementarse, el aumento persistente de peso desvela la posibilidad de que factores adicionales pueden coadyuvar a este aumento en el peso.

Algunos de los químicos con los que usualmente nos encontramos tienden a producir un cambio en el metabolismo de la célula grasa. El bisfenol A (BPA), fitoestrógenos, tributiltina (TBT), entre otros, han demostrado en estudios experimentales que pueden inducir un aumento en el peso en modelos en animales. A pesar de que los mecanismos mediante los que los disruptores endocrinos pueden inducir obesidad están en estudio, las modificaciones descritas hasta el momento llevan a considerar que el efecto en la expresión de los genes mediante la metilación del ADN y las variaciones covalentes de la cromatina son comunes y afectan a las generaciones siguientes. En este sentido se observa que las alteraciones epigenéticas son la causa de las alteraciones metabólicas inducidas por los "obesógenos" ambientales.

Dado que los estudios en humanos son muy difíciles de establecer, debido a que los efectos dependen del monto de 
la exposición y del tiempo en los que las personas han estado expuestas. Así mismo, el plantear estudios experimentales de cohortes o casos y controles no podrían pasar un comité de ética en ningún país desarrollado, sumado a las evidencias de envenenamientos accidentales como en Minamata (mercurio) o Kyushu, bifenilos policlorinados (PCB), son manifestación del gran riesgo en salud que pueden desencadenar estos quí- micos. Las evidencias de los estudios en animales son suficientes para buscar políticas que reduzcan la posibilidad de tener enfermedades inducidas por químicos.

La investigación en el ámbito de los disruptores endocrinos y obesidad está en su inicio, no obstante, la demostración en los estudios en animales es suficiente para crear sensibilidad en el daño que pueden generar estas sustancias.

\section{Conferencia}

\section{Microcarcinoma papilar de tiroides y vigilancia activa}

\section{Hernán Tala}

$\mathrm{E}$ n los últimos 30 años ha habido un aumento sustancial en la incidencia de cáncer de tiroides en los países desarrollados. Aproximadamente el $90 \%$ de este aumento corresponde al diagnóstico de tumores $<2 \mathrm{~cm}$ y el $50 \%$ al diagnóstico de microcarcinoma papilar de tiroides (mCPT) intratiroideos.

En un metanálisis de 989 autopsias, la prevalencia de mCPT oculto fue del $11.5 \%$. Asimismo, estudios realizados en tiroidectomía por enfermedad benigna muestran que al menos $10 \%$ de ellas presentan mCPT oculto. Estos representarían un reservorio importante de neoplasias tiroideas desconocidas. De hecho, la prevalencia de mCPT ocultos identificados en la autopsia es 100-1,000 veces mayor que la del cáncer clínico. Por otro lado, en Korea, la incidencia de cáncer de tiroides aumentó dramáticamente (hasta 15 veces) a partir del año 1999, luego de ofrecer screening con ecografía tiroidea a la población. Considerando lo anterior, se estima que este aumento de incidencia es secundario en gran medida al uso masivo de ecografía cervical y otros métodos de imágenes, así como a la mejor sensibilidad de estas técnicas, que logran identificar nódulos tan pequeños como 2-3 $\mathrm{mm}$, previamente no identificados por el examen físico, y que anteriormente formaban parte de un gran reservorio de cáncer de tiroides subclínico.

Indirectamente sugiere lo anterior el hecho que a pesar de este aumento de incidencia, la tasa de mortalidad por carcinoma papilar de tiroides sigue siendo baja y estable. Por otro lado, la mortalidad relacionada con el mCPT es muy baja, llegando hasta el $0,3 \%$, siendo cero cuando se excluye del análisis pacientes con metástasis ganglionares clínicas o a distancia al momento del diagnóstico (4-14). Respecto al riesgo de recurrencia, solo la presenta un $1 \%-5 \%$ de los pacientes con mCPT, reduciéndose a $<1 \%$ cuando se excluyen pacientes con metástasis ganglionares clínicas. Asimismo, la detección de estos mCPT, según lo demostrado en el estudio koreano, no logró beneficios en la ya muy baja mortalidad asociada a esta entidad.

Lo anterior nos hacen plantear que estamos enfrentando un sobrediagnóstico y sobretratamiento de mCPT, sometiendo a pacientes a costos económicos y emocionales, además de riesgos de complicaciones asociadas al tratamiento, por una condición que en general no causaría daño si no se trata.

Teniendo en cuenta la información antes detallada, es importante concientizar sobre dos importantes acciones:

1. No realizar tamizaje universal de cáncer de tiroides con ecografía cervical u otro método de imagen en la población general.

2. No proceder inmediatamente a cirugía en pacientes con diagnóstico de mCPT, y evaluar la posibilidad de vigilancia activa.

\section{Vigilancia activa en mCPT de bajo riesgo de morbilidad}

El manejo clínico de pacientes con diagnóstico de mCPT va a depender de la probabilidad de morbilidad asociada. En este sentido, se deben diferenciar dos tipos mCPT:

1. mCPT con alto riesgo de morbilidad: Presenta alguna de las siguientes características clínicas/radiológicas: 1) extensión extratiroidea; 2) invasión o riesgo de invasión traqueal o de nervio laríngeo recurrente; 3) metástasis linfonodal; 4) metástasis a distancia (Muy raro).

2. mCPT con bajo riesgo de morbilidad: No presenta ninguno de los elementos arriba mencionados.

Pacientes con mCPT con alto riesgo de morbilidad deben proceder a tratamiento quirúrgico. En cambio, aquellos pacientes que presenten mCPT con bajo riesgo de morbilidad, deben ser evaluados y evaluar la posibilidad de insertar en un programa de vigilancia activa, antes de indicar automáticamente cirugía.

Las bases para plantear vigilancia activa en pacientes con mCPT de bajo riesgo de morbilidad son las siguientes:

1. La minoría de los pacientes progresa y, en caso de progresión, esta es lenta.

2. En caso de progresión, la cirugía de rescate logra resultados similares y un buen pronóstico general.

3. Permite reducir el número de pacientes expuestos a las complicaciones quirúrgicas sin un claro beneficio asociado a la cirugía.

Hasta el momento existen cuatro estudios mayores que han evaluado la posibilidad de realizar vigilancia activa en pacientes con mCPT de bajo riesgo de morbilidad.

En el mayor de estos estudios, Ito y cols. siguieron a 1.235 pacientes de Japón por un promedio de cinco años. La probabilidad de progresión fue en general baja, siendo la edad el factor de riesgo más relevante asociado a progresión. A los 5 años de seguimiento, la probabilidad de progresión fue la siguiente:

1. En pacientes $>60$ años, solo $4 \%$ presentó crecimiento $\geq 3$ mm y solo $0,5 \%$ presentó metástasis linfonodal nueva. 
2. En pacientes entre 40 y 60 años, solo $5 \%$ presentó crecimiento $\geq 3 \mathrm{~mm}$ y solo $1.4 \%$ presentó metástasis linfonodal nueva.

3. En pacientes $<40$ años, solo $9 \%$ presentó crecimiento $\geq 3 \mathrm{~mm}$ y solo $5 \%$ presentó metástasis linfonodal nueva.

De los 1.235 pacientes, 16\% fueron sometidos finalmente a tiroidectomía y seguidos por un promedio de 6,3 años. Solo presentó recurrencia 1 paciente 10 años después de la cirugía. No se presentó muerte ni desarrollo de metástasis a distancia en ninguno de los pacientes que continuaban en vigilancia activa, ni en los pacientes operados. Los otros tres estudios publicados presentan resultados relativamente similares.

Al momento de considerar la posibilidad de vigilancia activa se deben tener en cuenta características ecográficas y clínicas del tumor, características del paciente y características del centro clínico:

1. El tumor debe reunir elementos clínicos y ecográficos que permitan considerarlo como de bajo riesgo de morbilidad.

2. Características del paciente: Debe presentar características psicológicas y culturales y sociales adecuadas, que permitan, entre otras, la posibilidad de acudir de manera regular a control médico. Por otro lado, está contraindicado en pacientes $<18$ años, e ideal en pacientes mayores, donde el riesgo de progresión es aun menor.

3. Características del centro clínico: Es importante que sea realizado en un centro clínico con experiencia en cáncer de tiroides, donde exista un sistema informático que permita rastreo de pacientes y alertas en caso de inasistencia a controles, así como la disponibilidad de ecografía cervical de calidad, cirujanos y endocrinólogos con experiencia.

El seguimiento debe ser realizado por un equipo dedicado y con experiencia, debe incluir una ultrasonografía cervical realizada por experto en tiroides, con análisis detallado de los linfonodos cervicales. Los controles deben realizarse inicialmente cada 6-12 meses y, si estable por al menos dos años, luego anual. Es importante tener un sistema de rastreo con alarma, para detectar pacientes que se pierdan de seguimiento.

\section{Conclusión}

Existe un aumento importante en la incidencia de cáncer papilar de tiroides a nivel mundial, principalmente debido a la detección de mCPT por el uso masivo e indiscriminado de imágenes de alta resolución. Una proporción importante corresponde a mCPT de bajo riesgo de morbilidad, con baja probabilidad de progresión y daño. La cirugía inmediata para mCPT de bajo riesgo podría exponer a una alta proporción de pacientes a efectos secundarios, ansiedad y costos, sin beneficio aparente en una condición con baja probabilidad de generar daño si no es tratado. Un programa correctamente implementado de vigilancia activa parece ser una opción viable para pacientes seleccionados adecuadamente con $\mathrm{mPTC}$ de bajo riesgo, seguidos en centros especializados.

\section{Conferencia}

\section{The old and new times in treatment for osteoporosis? What medication for whom, sequence and duration of} treatment?

\author{
Michael McClung
}

$\mathrm{O}$ steoporosis is a chronic condition of increased fracture risk requiring long-term treatment. Over the past 25 years, multiple medicines in several classes with very different mechanisms of action have become available for the treatment of osteoporosis in postmenopausal women and men. The clinical trials demonstrating fracture risk reduction were, until recently, classic placebo controlled trials lasting 3-5 years. Long-term safety and effectiveness was evaluated in extensions of the pivotal Phase 3 studies in which there was no placebo group and often limited numbers of patents and fractures. While there were many studies evaluating BMD responses to various combinations and sequences of treatment and several head-to-head studies comparing BMD responses to different treatments, none of these studies was large enough to compare fracture rates between treatments or regimens.

Based upon these studies, oral and IV bisphosphonates, denosumab and raloxifene, were considered appropriate first-line drugs for patients at moderate risk of fracture while denosumab, zoledronic acid and teriparatide were drugs recommended for patients at high risk of fracture. Raloxifene has a special role in the treatment of younger postmenopausal women at risk for spine fracture but at low risk of hip fracture, especially in those women at risk for breast cancer. Teriparatide has generally been reserved as treatment for patients at high or imminent risk of vertebral fracture, while bisphosphonates and denosumab are thought to be appropriate treatments for almost all patients.

There is never a role for combining anti-remodeling agents for the treatment of osteoporosis. Combining bisphosphonates and teriparatide does not provide significant advantage over monotherapy. The combination of denosumab and teriparatide results in faster and larger increases in BMD than either drug alone. However, this additional BMD gain is accompanied by a decrease in bone formation, raising questions about whether the BMD advantage of combined therapy 
has the same anabolic effect in trabecular bone that we expect with teriparatide. In the absence of good evidence of better protection from fracture, simultaneous use of osteoporosis drugs cannot be recommended.

Three recent Phase 3 fracture studies have evaluated the sequence of an anabolic agent (abaloparatide or romosozumab) followed by a potent anti-remodeling drug (alendronate or denosumab) compared to alendronate or to placebo followed by an anti-remodeling drug. In each study, beginning therapy with an anabolic agent, followed by the anti-remodeling drug, was more effective in reducing fracture risk than was starting the anti-remodeling drug. The sequences evaluated in the clinical trials are or will be a part of the approved prescribing information.

In support of the notion that high risk patients should be treated initially with an anabolic agent for 1-2 years, the recent results of the VERO study demonstrated that therapy with teriparatide for 24 months reduced the risk of vertebral and clinical fractures more quickly and to a greater extent than did risedronate in women with postmenopausal osteoporosis at high fracture risk. Collectively, these new findings make it clear that physicians and payers should consider starting treatment in patients at very high risk of fracture with a bone-building, anabolic drug for 12-24 months, followed then by an anti-modeling agent like denosumab or a bisphosphonate.

There is no limit to the duration of raloxifene therapy. However, as the patient's risk of hip fracture becomes a clini- cal concern, switching to a drug known to reduce hip fracture risk would be appropriate. The use of teriparatide is limited by regulatory rule to $18-24$ months, after which follow-on therapy with a bisphosphonate or denosumab is appropriate. The pharmacology of bisphosphonates is unique; because of tight binding of the drugs to bone matrix, the offset of effect on bone remodeling when treatment is stopped is quite slow. However, protection from vertebral fracture wanes over 3-5 years after discontinuing therapy. This has led to recommendations that therapy be continued in patients who remain at high risk of fracture after 3-5 years of bisphosphonate therapy while a "bisphosphonate holiday" could be considered in patients thought to be at lower risk of fracture after 3-5 years therapy. Switching from a bisphosphonate to denosumab results in progressive gains in BMD whereas hip BMD values plateau after 5 years of bisphosphonate therapy. Thus, for those patients remaining at high fracture risk after 5 years of bisphosphonate therapy, switching to denosumab rather than continuing the bisphosphonate might be considered. There is no limit to the duration of denosumab therapy. If therapy is stopped, switching to a bisphosphonate for 1-2 years should be considered to prevent the rebound in bone remodeling, the rapid loss of bone density and of protection from vertebral fractures.

Summary: Treating patients with osteoporosis requires a long-term management plan. Therapy is individualized depending on the patient's age, fracture risk and other clinical considerations.

\title{
Conferencia
}

\section{Diabetes, osteoporosis and obesity: are they related?}

\author{
Michael McClung, MD
}

$\mathrm{O}$ steoporosis is a chronic disorder characterized by low bone mass and skeletal deterioration resulting in impaired bone strength and increased risk of fracture. Based on studies demonstrating a strong relationship between BMD and fracture risk, osteoporosis is now defined by bone mineral density (BMD) criteria, when postmenopausal women have a T-score of -2.5 or lower in the lumbar spine or proximal femur. Thus, osteoporosis is an important but not the only risk factor for fragility fracture. Approximately $20 \%$ of women aged 50 years and older are classified as having osteoporosis by these BMD criteria.

BMD by DXA testing is strongly correlated with body weight; low body weight is associated with low BMD and increased risk of hip fracture. Conversely, high body weight is associated with high BMD. However, recent studies have demonstrated that patients with obesity and type 2 diabetes, despite having increased bone density, are at increased risk for fracture, relative to their BMD, compared to non-diabetic patients of normal weight. Among those aged 60 years and older in the United States, $42 \%$ of women and $37 \%$ of men are obese. Thus both disorders are considered to be significant health care is- sues in the modern society, and they are commonly encountered together.

It appears that patients with obesity are particularly prone to fractures of the lower extremity while being at average or lower risk for hip and spine fractures, those typically associated with osteoporosis. The fracture diathesis in obesity with or without diabetes may be related simply to increased skeletal loading due to the increased weight which, in some patients, appears to be greater than the increased bone strength conveyed by higher BMD.

The relationship between diabetes and fracture risk is more complex. Patients with Type 1 diabetes, especially if it began in childhood, have lower than average BMD. However, the fracture risk In both Type 1 and Type 2 diabetes is greater than the BMD would portend. The pathophysiology of the fracture risk in patients with diabetes is not known. Some patients some studies have demonstrated increased cortical per recipe and put regular microarchitecture in patients with type two diabetes. Bio chemical into Cesar bone formation are generally low in patients with diabetes, perhaps due to low serum IGF-I levels. Increased glycation of new matrix 
proteins is increased in diabetic patients, perhaps resulting in skeletal brittleness.

In summary, neither obesity nor type 2 diabetes causes osteoporosis (low BMD), but all 3 disorders are important and independent risk factors for fracture. Importantly, BMD remains a risk factor for fracture both in obesity and diabetes; patients with these disorders are just at higher risk of fracture at any level of BMD than are non-obese, non-diabetic patients at the same age and with the same BMD. That increased fracture risk must be considered when evaluating fracture risk in patients with obesity and diabetes.

\title{
Conferencia
}

\section{Deregulation of non-coding RNAs in thyroid cancer}

\author{
Alfredo Fusco, Pierlorenzo Pallante, Romina Sepe, Simona Pellecchia, Marco De Martino, Francesco Esposito, \\ Alfredo Fusco
}

I nstitute for Experimental Endocrinology and Oncology (IEOS) “G. Salvatore”, National Research Council (CNR) and Department of Molecular Medicine and Medical Biotechnology, University of Naples "Federico II", Naples, Italy.

It has been recently evidenced that the non-coding RNAs (ncRNAs) play crucial and pleiotropic roles in the regulation of many cellular functions. They are transcribed by a very large portion of the genome (up to 98\%) that does not code for proteins. In the recent years, three subcategories of ncRNAs, including microRNAs (miRNAs), long non-coding RNAs (lncRNAs) and pseudogenes, have been widely investigated in thyroid cancer.

Through a miRNACHIP microarray genome-wide analysis of human thyroid papillary carcinomas (PTCs) in comparison to normal thyroid tissues, we identified a miRNA signature strictly associated with PTCs. This molecular signature, characterized by the strong overexpression of miR-221, -222 and $-181 \mathrm{~b}$, was further confirmed in PTC samples by quantitative (q)RT-PCR. Interestingly, this signature was also observed in fine-needle aspiration specimens suspected for PTC, and confirmed after surgery. We also found that animal models of thyroid carcinogenesis showed very high levels of miR-221, -222 and $-181 b$.

Subsequently, we identified p27(Kip1) gene as one of the molecular target of miR-221 and -222, as anticipated by bioinformatics target prediction algorithms. Indeed, transfection of miR-221 and -222 lowered the p27(Kip1) protein levels, while mRNAs levels remained unchanged suggesting an effect of miR-221/22 at translational level. Consistently, in mR-221/222-transfected PTC-derived cell lines the entry into phase $S$ of the cell cycle was faster in comparusin to the untransfected control cells. This mechanism of cell cycle regulation has likely a role also in vivo, as pointed out by the expression levels of p27(Kip1) protein that in human PTCs resulted inversely correlated with miR-221 and -222 levels.

Then, we moved toward a miRNA characterization of anaplastic thyroid carcinomas (ATC). In this case the signature that we obtained was characterized by the strong reduction of miR-30d, -125b, -26a and -30a-5p in ATC samples, with respect to the normal thyroid tissue controls. Additionally, we demonstrated that miR-25 and -30d target the the oncogenic protein enhancer of zeste 2 (EZH2) whose overexpression has been detected in ATC samples, but not in differentiated thyroid carcinomas, then indirectly confirming the existence of a regu- latory mechanism of miR-25 and -30d on EZH2 expression. Finally, restoration of miR-25 and -30d in ATC cell lines induced a block of the cell cycle in the G2/M phase, with a consequent slowdown of cell proliferation.

We have characterized two pseudogenes of HMGA1 (HMGA1P6 and HMGA1P7) as far as their involvement in cancer progression is concerned, in our laboratory. We observed that the overexpression of these two pseudogenes is able to release HMGA1 and other cancer-related proteins from the regulation of several microRNAs. In fact, embryonic fibroblasts obtained from a transgenic mouse overexpressing HMGA1P7 exhibited increased growth rate together with an escaping from senescence mechanisms. Additionally, in vivo expression analysis revealed that ATC, one of the most aggressive human cancer, but not in differentiated thyroid carcinomas, showed high levels of HMGA1P6 and HMGA1P7, strictly correlated to those of HMGA1 in the same cancer type, thus suggesting a critical role of pseudgenes in cancer progression.

Very recently, we also evaluated the involvement of IncRNA in thyroid carcinogenesis, by using a IncRNA expression array hybridized with 12 PTC samples in comparison with 4 normal thyroid tissues. Interestingly, we found that 669 lncRNAs resulted upregulated, while 2470 resulted downregulated in PTCs in comparison to normal controls. After validating the IncARRAY data by using qRT-PCR, we focused on the cancer role of the downregulated IncRNA RP5-1024C24.1, that on the chromatin is associated in antisense position with the MPPED2 gene. This latter encodes a metallo-phospho-esterase showing tumor suppressor activity in several neoplasias. The expression of these two genes, evaluated by by qRT-PCR and immunohistochemistry, is positively associated in benign and malignant thyroid tumors, where both the genes were signifiacantly downregulared.

The putative tumor supressor role of either RP51024C24.1 and MPPED2 was functionally confirmed by transfection experiments in thyroid carcinoma cell lines, where their enforced expression was able to reduce cell proliferation rate and migration through a mechanism involving AKT inactivation. Additionally, we also confirmed that RP5-1024C24.1 is able to restore the expression levels of MPPED2. In conclusion, these results strongly indicate that the reduced levels of both RP5-1024C24.1 and the associated MPPED2 protein take a part in the human carcinogenesis process. 


\title{
Conferencia
}

\section{The new understanding of type 2 diabetes - simplicity} revealed

\author{
Roy Taylor
}

Professor of Medicine and Metabolism, Newcastle University, UK

$\mathrm{T}$ he lifelong nature of type 2 diabetes has always appeared self-evident. Observational studies have documented the gradual worsening of blood glucose control with need for increasing numbers of oral hypoglycaemic agents. By 10 years after diagnosis, $50 \%$ of people require insulin therapy to achieve reasonable control. As a consequence of these findings, it is common practice to inform individuals at the time of diagnosis that they have a lifelong condition. The importance of accepting this inevitability has been emphasised. The overall result is a learned helplessness on the part of both patients and health care professionals.

Work in the last few years has shown that type 2 diabetes is a simple condition of fat excess, which can readily be reversed to normal at least in the early years.

Using a low energy diet as a tool, it has been possible to elucidate the sequence of pathophysiological changes which lead to the reversal of type 2 diabetes to normal. This decade-long research endeavour was driven by the predictions of the 2008 Twin Cycle hypothesis which presented a new analysis of the aetiology of type 2 diabetes. It was postulated that long term, modest calorie excess led to accumulation of liver fat. The consequent liver insulin resistance led to increased fasting plasma insulin levels. But insulin itself drives on the accumulation of liver fat. Eventually, this results in increased export of fat to the rest of the body, and excess fat is transported to the pancreas. Chronic exposure to excess fat is known to impair the acute response of beta cells to an increase in plasma glucose. And as the years passed by, the greater and prolonged rise in post-meal plasma glucose would both cause higher basal insulin and more accumulation of liver fat. Essentially, two vicious cycles interacted.

It proved possible to test this hypothesis and to observe the pathophysiological changes allowing the disease to be normalised. Using the research tool of a low energy diet $(\sim 700 \mathrm{kcal} /$ day), a 30\% fall in liver fat content with normalisation of hepatic insulin sensitivity was observed within 7 days. As a result, fasting plasma glucose normalised. These observations confirmed the liver cycle portion of the Twin Cycle Hypothesis. Over 8 weeks of the diet, the liver fat content fell dramatically and secondary to this, the raised intra-pancreatic fat content gradually fell over 8 weeks with return of first phase insulin secretion. For the first time, it was possible to describe the simplicity of type 2 diabetes - a disease that rapidly increases in prevalence when a population is overfed, and rapidly disappears when a population is in marginal calorie balance.

A second, larger study established that duration of type 2 diabetes was the most important factor in whether or not beta cell function could be restored after adequate weight loss. For groups of duration $<4$ years and $8-23$ years, $90 \%$ and $50 \%$ respectively returned to non-diabetic glucose control. No-one with duration $>11$ years demonstrated reversal of diabetes, reflecting the eventual loss of beta cell capacity for redifferentiation.

One important question was whether it was possible to deliver calorie restriction, and continued weight control, to a population using Primary Care nurses or dietitians. DiRECT (Diabetes Remission Clinical Trial) was published last December. This study was conducted in conjunction with Professor Mike Lean of Glasgow. Participants were randomised to either control or Intervention arms. Control participants continued usual medications and all dietary and other care according to best-practice guidelines. The Intervention participants stopped all anti-diabetic and antihypertensive medication on day 1 , and followed an $825-853 \mathrm{kcal} /$ day liquid formula diet for 3-5 months followed by a stepped return to isocaloric eating of normal foods. The whole intervention is known as Counterweight Plus.

DiRECT showed that the routine health service staff could be trained to deliver the intervention. The study was oversubscribed by people very keen to reverse their diabetes. Doctors have tended not to realise how much the condition is hated by many patients. After a low calorie weight loss period then follow up, by 12 months $25 \%$ of the group were still more than $15 \mathrm{~kg}$ lighter than at baseline, and $46 \%$ were in remission of diabetes, off all anti-diabetic medication. The study will continue to follow up these individuals for a total of 5 years. Maintain of stable weight after the weight loss period is good to date. However, it remains to be demonstrated how best to achieve this. The principles of regular review, involvement of family and provision of clear advice are beyond doubt.

It is clear that early type 2 diabetes is a simple, reversible condition of fat excess in pancreas and liver. It is often described as a 'complex, heterogeneity condition', but the complexity lies in the individuals, not in the disease process itself. 